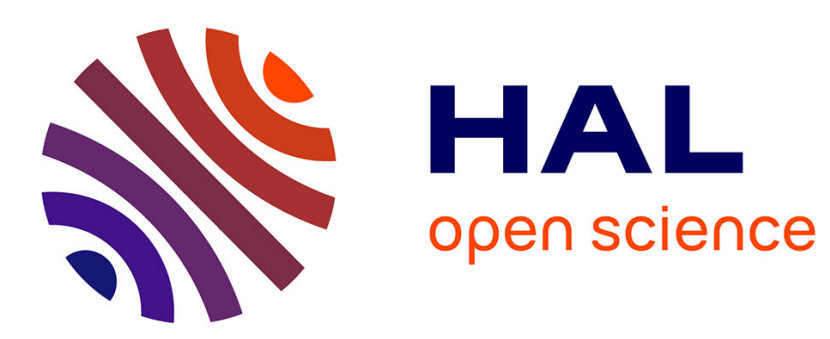

\title{
Jean-Baptiste Vietty et l'Expédition de Morée (1829) : À propos de deux manuscrits retrouvés
}

Stéphane Gioanni

\section{To cite this version:}

Stéphane Gioanni. Jean-Baptiste Vietty et l'Expédition de Morée (1829): À propos de deux manuscrits retrouvés. Journal des Savants, 2008, 2 (1), pp.383 - 429. 10.3406/jds.2008.5891 . halshs01756006

\section{HAL Id: halshs-01756006 \\ https://shs.hal.science/halshs-01756006}

Submitted on 31 Mar 2018

HAL is a multi-disciplinary open access archive for the deposit and dissemination of scientific research documents, whether they are published or not. The documents may come from teaching and research institutions in France or abroad, or from public or private research centers.
L'archive ouverte pluridisciplinaire HAL, est destinée au dépôt et à la diffusion de documents scientifiques de niveau recherche, publiés ou non, émanant des établissements d'enseignement et de recherche français ou étrangers, des laboratoires publics ou privés. 


\title{
JOUR N A L D E S
}
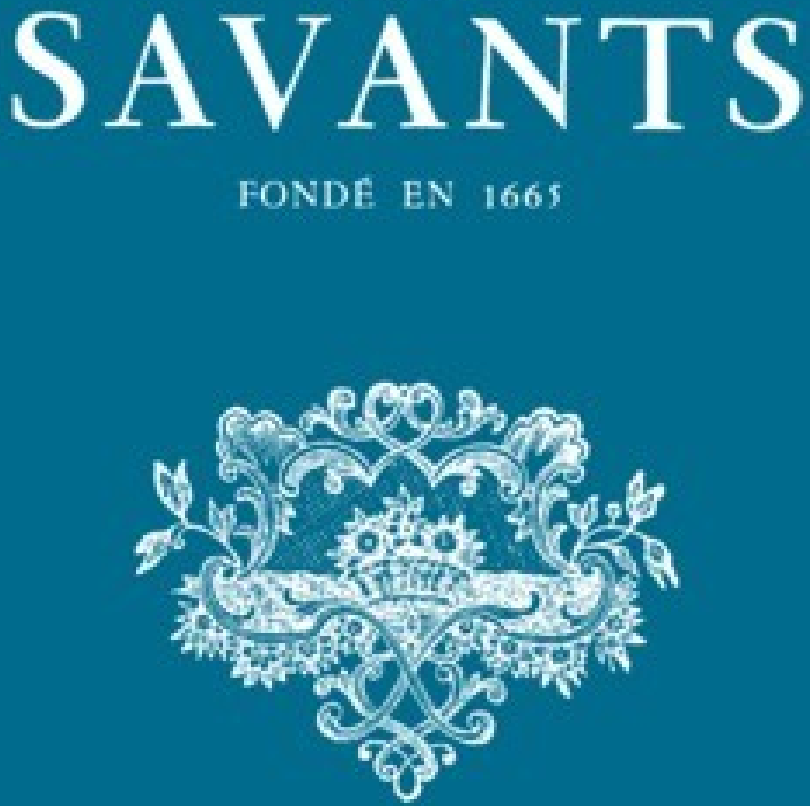

\author{
PARIS \\ DIFFUSION DE BOCCARD
}




\section{Jean-Baptiste Vietty et l'Expédition de Morée (1829) : À propos} de deux manuscrits retrouvés

\section{Monsieur Stéphane GIOANNI}

\section{Citer ce document / Cite this document :}

GIOANNI Stéphane. Jean-Baptiste Vietty et l'Expédition de Morée (1829) : À propos de deux manuscrits retrouvés. In: Journal des savants, 2008, $n^{\circ}$ pp. 383-429.

doi : 10.3406/jds.2008.5891

http://www.persee.fr/doc/jds_0021-8103_2008_num_2_1_5891

Document généré le 21/10/2015 


\section{JEAN-BAPTISTE VIETTY ET L'EXPÉDITION DE MORÉE (I829): À PROPOS DE DEUX MANUSCRITS RETROUVÉS*}

L'Expédition scientifique de Morée, de mars à décembre I829, marque une étape majeure dans l'étude de la Grèce et, plus largement, dans l'histoire de l'archéo-

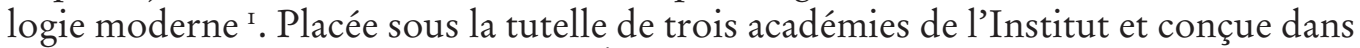
le même esprit que l'Expédition d'Égypte, elle mit un terme à l'hellénisme ${ }^{2}$ élégiaque des voyageurs ${ }^{3}$ et au pillage systématique des monuments antiques, ouvrant la voie à «la véritable découverte scientifique du pays qui s'effectua dans la deuxième moitié du XIX ${ }^{e}$ siècle ${ }^{4}$ ». Cette mission, associée à des découvertes exceptionnelles comme le temple de Zeus à Olympie, fut à l'origine de la présence permanente des archéologues français dans le pays et de la fondation en I 846 de l'École française d'Athènes.

* Je tiens à exprimer ma reconnaissance aux Professeurs Jean Marcadé et Jean-Louis Ferrary, membres de l'Institut, et au Professeur Laurent Feller, de l'université Paris I, qui m'ont fait profiter de leurs précieux conseils. Je remercie également le musée des Beaux-Arts de Lyon qui m’a autorisé à reproduire une œuvre de Jean-Baptiste Vietty.

I. Voir L'Invention scientifique de la Méditerranée. Égypte, Morée, Algérie, M.-N. Bourguet, B. Lepetit, D. Nordman, M. Sinarellis dir., Paris, I998, 325 p. : la mission scientifique en Morée fait suite à l'intervention militaire de la France en faveur des Grecs durant la Guerre d'indépendance (I 82 I-I 829 ). Après la victoire sur la flotte turco-égyptienne dans la rade de Navarin, en octobre I 827 , et la libération du Péloponnèse par le corps expéditionnaire du général Maison, au cours de l'année i 828 , le groupe de savants français débarqua à Navarin le 3 mars I 829.

2. Sur l'histoire de la notion d'hellénisme, voir N. Sigalas, «Hellénistes, hellénisme et idéologie nationale. De la formation du concept d'hellénisme ", dans L'Antiquité grecque au XIXe siècle. Un exemplum contesté ?, Chr. Avlami éd., Paris, 2000, p. 239-291.

3. Le Voyage du jeune Anacharsis en Grèce, publié en I 788 par l'abbé Jean-Jacques Barthélemy, est l'une des meilleures illustrations de la vision idéale de la Grèce nourrie depuis la Renaissance.

4. R. ÉTIENNE «Quand les premiers archéologues découvrirent la Grèce », dans Clio.fr, 2007 ; R. ÉTIENNE, ancien directeur de l'École française d'Athènes, a publié notamment La Grèce antique, archéologie d'une déconverte, Paris, I990; voir aussi E. GRAN-AYMERICH, Naissance de l'archéologie moderne. I798-1945, Paris, I998. 
Deux manuscrits anonymes, renfermant les notes de travail de l'un des membres de la section d'archéologie de juillet à novembre i 829, viennent d'être retrouvés s. Ils ont été rédigés par le sculpteur et helléniste Jean-Baptiste Vietty (I787-I 842) qui poursuivit ses recherches en Grèce jusqu'en août I83 I et qui fut chargé, après l'examen de ses manuscrits par l'Institut, de publier un ouvrage rassemblant la totalité de ses découvertes, le plus souvent inédites. L'ampleur du projet, la mort précoce de Vietty "dans une grande misère ${ }^{6}$ » et la disparition de tous ses manuscrits avaient malheureusement empêché toute publication de ses travaux et précipité dans l'oubli cette vaste entreprise d'érudition.

Le souvenir de Vietty se limite aujourd'hui au bronze d'Apollon qui surplombe la fontaine du jardin du palais des Beaux-Arts, à Lyon, et à quelques œuvres éparses. Au début du XXe siècle, Léon Charvet avait consacré une longue étude au savant lyonnais ${ }^{7}$ dans l'espoir qu'on puisse un jour retrouver ses manuscrits et « renouer la chaîne brisée, en commençant par consulter (...) le dossier de Vietty, aux papiers de la Commission de Morée, lesquels furent transportés, avec les archives du ministère de l'Intérieur, en I 870, aux Archives nationales ${ }^{8}$ ». D'autres commentateurs, depuis, se sont montrés moins indulgents après avoir consulté les papiers autographes ${ }^{9}$ : "Jean-Baptiste Vietty (I787-I 842), se dit "statuaire", élève du médailliste Cartelier; il a été en I 820 distingué par l'Institut pour diriger des travaux de sculpture à la Bourse de Saint-Pétersbourg et s'est vu attribuer une médaille d'or au Salon de i 824. Originaire de la région lyonnaise, il s'est consacré à un long travail sur les antiquités de Vienne qui sera publié en $1830^{10}[\ldots]$. En dépit de ces aptitudes prometteuses, sa participation aux travaux de l'Expédition [de Morée] sera réduite à néant : on attendra en vain l'envoi de ses œuvres, retardé par un état mental préoccupant. Les manuscrits de Vietty, que l'on peut consulter aujourd'hui, sont sans intérêt, pauvres en dessins et remplis de considérations

5. Carnets $\mathrm{n}^{\circ} \mathrm{I} 2$ et $\mathrm{n}^{\circ} 24$; anonymes ; 20 sur I $4 \mathrm{~cm}$; couvertures de cuir défraîchies ; 160 pages x 2 ; coll. particulière. Ces manuscrits ont été achetés à la « librairie niçoise » de M. Thierry Desouche.

6. Archives nationales, F 2 I 545 : lettre du géologue Virlet d'Aoust, membre de l'Expédition de Morée, au ministre de l'Intérieur (io avril i 843).

7. L. Charvet, "Jean-Baptiste Vietty », Réunion des Sociétés des Beaux-Arts, 34, I910, p. 3 I-53 ; 35 , I9II, p. I92-239.

8. Id., Réunion des Sociétés des Beaux-Arts, 35, I9I I, p. 239. Les archives de la Commission de Morée sont conservées aux Archives nationales sous les côtes F 2 I 544 et F 2 I 545.

9. Archives nationales, F 2 I 545: il s'agit de son dossier de candidature à l'Expédition, de quatre lettres administratives et de quelques feuilles incohérentes rédigées à la fin de sa vie.

Io. E. REY et E. VIETTY, Monuments romains et gothiques de Vienne en France dessinés et publiés par E. Rey, suivis d'un texte historique et analytique par E. Vietty, Paris, I83 I. Pou la forme «E. Vietty", cf. n. 2 I. 
fumeuses ${ }^{\mathrm{II}}$. » Ces documents de Vietty, rédigés quelques semaines avant sa mort, sont assez décevants, il est vrai, mais ils n'ont aucun rapport avec ses manuscrits de travail qui avaient disparu depuis le milieu du XIX siècle.

Les deux carnets retrouvés sont une infime partie des «cent onze liasses, carnets ou cahiers » recensées en I 848 par le dépositaire judiciaire de ses affaires qui signale aussi «cent sept médailles grecques renfermées dans un sac de toile ${ }^{\mathrm{I} 2}$ ". Nous avons pensé qu'une présentation de ces deux manuscrits et la transcription de quelques extraits donneraient aux spécialistes une idée de l'apport documentaire des travaux de Vietty et fourniraient peut-être des indices pour retrouver le reste de l'œuvre engloutie.

\section{LES MANUSCRITS DE JEAN-BAPTISTE VIETTY}

\section{L'auteur des carnets}

Les travaux de la Commission d'architecture et de sculpture, annoncés officiellement au monde savant en I $83 \mathrm{I}^{\mathrm{I} 3}$, furent publiés sous l'égide de l'Institut de France entre I83I et I838 I4. Ces ouvrages scientifiques furent accompagnés de récits de voyage publiés par des membres de l'Expédition après leur retour en France ${ }^{\mathrm{Is}}$. Ces récits personnels racontent la vie quotidienne des savants et les difficultés auxquelles ils étaient confrontés dans un pays dévasté par la guerre. Plusieurs d'entre eux tombè-

I I. Chr. Peltre, Retour en Arcadie. Le voyage des artistes français en Grèce au XIX siècle, Paris, I997, p. 93. L'auteur renvoie en note aux manuscrits conservés aux Archives nationales sous la côte F 2 I 545 .

I 2. Archives du cabinet des Médailles, i I AMC 23 : documents sur les manuscrits et le médaillier laissés par feu Eugène Vietty, membre de la Commission scientifique du Péloponnèse. Ce dossier contient notamment un extrait du Mémoire adressé par M. Peyré au préfet du Rhône où figure l'inventaire des manuscrits de Vietty.

I3. Le 30 avril i93 I, M. Raoul Rochette, membre de la Commission de Morée pour l'Académie des inscriptions et belles lettres, annonça en séance publique les travaux de la section d'architecture et de sculpture, en particulier la découverte du sanctuaire de Zeus à Olympie. La redécouverte de nombreux sites perdus, la possession de fragments de sculpture et l'exploration méticuleuse des villes et des monuments inauguraient une ère nouvelle dans la perception de l'Antiquité. L'Expédition de Morée, grâce à Blouet et ses collaborateurs Ravoisié, Poirot, Trézel et Gournay, avait sauvé d'une destruction certaine les derniers débris de la civilisation grecque. Des extraits du rapport de M. Raoul-Rochette, lu à la séance publique des quatre académies, sont cités dans Expédition scientifique de Morée (op. cit. n. suivante), vol. I, p. 62-64.

I4. Expédition scientifique de Morée : architecture, sculptures, inscriptions et vues du Péloponnèse, des Cyclades et de l'Attique mesurées, dessinées, recueillies et publiées, A. BlouET dir., 3 vol., Paris, I 83 I-I 838. Les travaux de la Commission de sciences physiques furent publiés à partir de I 832 : Expédition scientifique de Morée: Section des sciences physiques, M. BORY DE SAINT-VInCENT dir., Paris, I832-I 836.

i s. J. B. BORY DE SAINT-VINCENT, Relation du voyage de la Commission scientifique de Morée dans le Péloponnèse, les Cyclades et l'Attique, Levrault, I836-I838, 2 vol. et un atlas; E. QuiNET, La Grèce moderne et ses rapports avec l'Antiquité; (suivie du) Journal de voyage, introduction, établissement des textes, notes par W. Aeschimann et J. Tucoo-Chala, Paris, I984; Amaury Duval, Souvenirs (I829-I830), Paris, i885. 
rent gravement malades et durent rentrer bien avant le terme de l'Expédition, à commencer par Amaury Duval et Edgar Quinet. Un petit carnet inédit du peintre Félix Trézel insiste sur les dangers de ces fièvres qui obligèrent également le chef de la section, M. Dubois, à quitter le pays ${ }^{16}$. Trézel continua le voyage « seul » à partir du mois de juillet I 829 et, de retour en France, il s'associa à la publication de la Commission d'architecture sous la direction d'Abel Blouet.

Les deux manuscrits jusqu'ici inconnus apportent un éclairage nouveau sur les travaux archéologiques de l'Expédition de Morée. Il s'agit de deux carnets de travail strictement identiques, formant un ensemble de 320 pages, sans rapport avec les souvenirs anecdotiques d'Amaury Duval et de Félix Trézel. Ils apparaissent, au premier regard, comme deux récits anonymes, sans titre, agrémentés de nombreux croquis de monuments et de paysages grecs, d'inscriptions lapidaires et de réflexions sur les objets et les lieux étudiés. La précision des relevés techniques, la maîtrise des langues anciennes et la connaissance des historiens antiques, notamment Pausanias et Thucydide, indiquent que l'auteur n'est pas un simple amateur de la Grèce antique.

L'écriture cursive, difficile à déchiffrer, révèle qu'il s'agit des carnets de travail d'un archéologue étudiant le Péloponnèse de juillet à novembre I829 (fig. I). La date, l'itinéraire, les allusions à Blouet ${ }^{17}$, Trézel ${ }^{18}$, membres de l'Expédition scientifique de Morée, et à « l'Expédition ${ }^{19}$ » elle-même laissent supposer que l'auteur des carnets appartenait lui aussi à la mission française. Trois éléments permettent d'identifier cet auteur : le premier, d'ordre paléographique, consiste à comparer l'écriture tourmentée des manuscrits aux documents rédigés par les membres de l'Expédition, en particulier leurs dossiers de candidature ${ }^{20}$. Malgré la différence de nature entre des notes cursives et des lettres officielles (fig. 2), on est vite tenté d'attribuer les carnets au sculpteur et helléniste Jean-Baptiste Vietty $(\mathrm{I} 787-\mathrm{I} 842)^{21}$, ancien élève de Chinard à l’École spéciale des arts et du dessin de Lyon.

16. Journal de voyage de M. Trézel (inédit), Bibliothèque nationale de France, n. acq. fr. I 849,35 fol.

I7. Carnet I 2, p. 7I : «Le côté latéral sud du Parthénon, la plaine d'où s'élèvent les huit grandes colonnes du Portique d'Hadrien, le monument de Philopappos en avant (ou la tour vénitienne des Propylées ([d'après] Blouet]). »

I 8. Carnet I2, p. 2 : "Selon M. Trézel, il y a une porte majeure et des forts avancés à l'avant de Sicyone, à l'endroit où j'avais aperçu des constructions helléniques (visendum est). »

I9. Carnet I2, p. 38 : «Je voulais faire fouiller quelques tombeaux mais la position subalterne dans laquelle on m'a placé en une telle Expédition ne m’en a pas laissé, ni le temps, ni les moyens. »

20. Archives nationales, F 2 I 544.

2 I. Jean-Baptiste Vietty, né en $\mathrm{I} 787$, se présente lui-même comme "Eugène Vietty [...] né en I79I ». Léon Charvet émet une hypothèse pour expliquer cette double incohérence qui est la source de nombreuses confusions : L. Charvet, "Jean-Baptiste Vietty ", Réunion des Sociétés des Beaux-Arts, 34, i910, p. 46 : «Les concurrents aux grands prix de l'Académie de peinture et de sculpture [...] ne pouvant se présenter après l'âge de trente ans, cela explique que notre Jean-Baptiste usa d'un subterfuge bien innocent, pour se rajeunir de quatre ans, en se faisant inscrire, le 27 août I 8 I 7, sous le nom de son frère, Claude-Marie-Eugène (né le i I avril i79I). » 


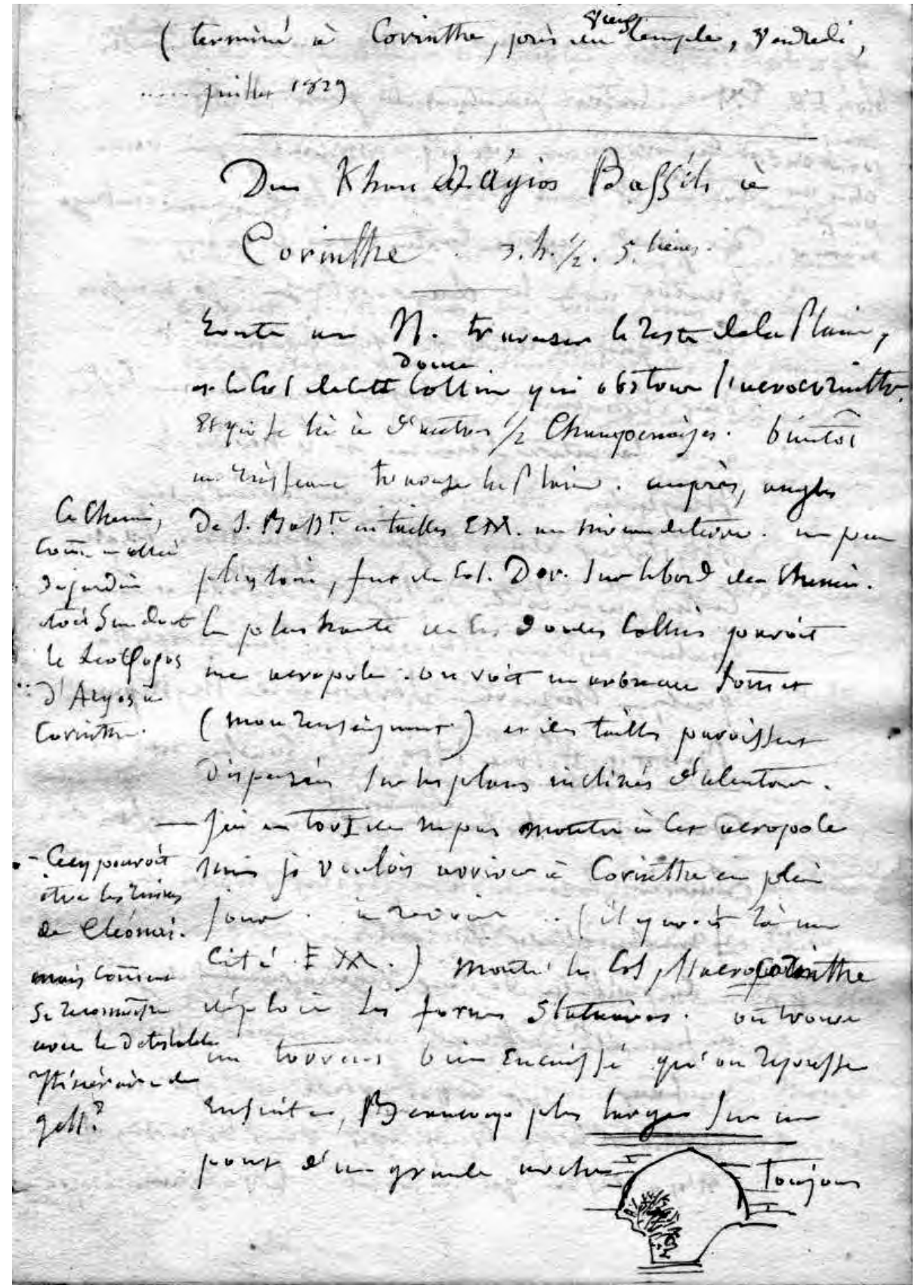

FIG. I. - Extrait du carnet 24, p. 45 (juillet I 829). 


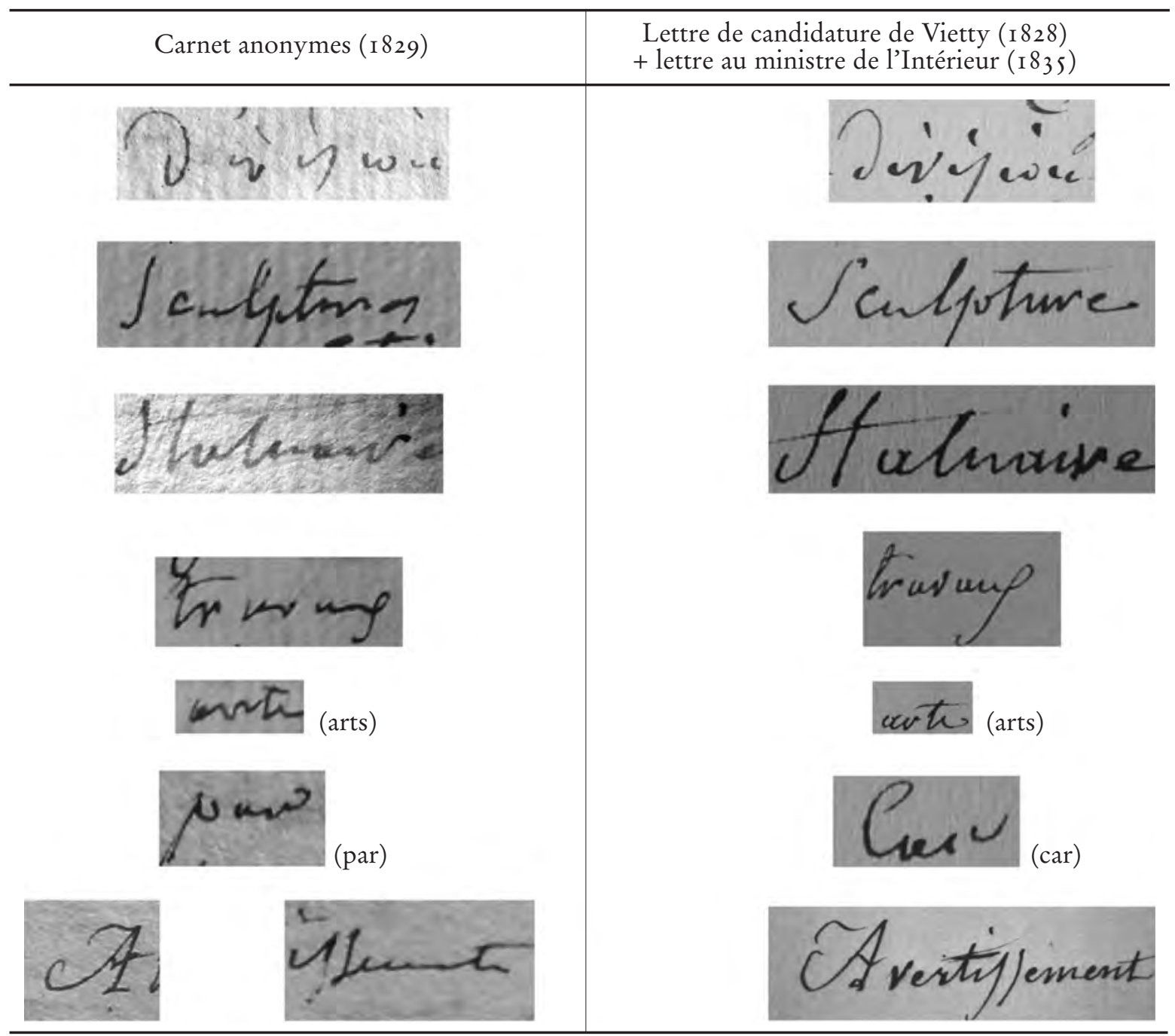

FIG. 2. - Comparaison des carnets anonymes avec des Correspondances de Vichy. 
La lecture du récit renforce cette hypothèse d'attribution. L'auteur décrit les pins de Salamine puis ceux d'Épidaure en soulignant, au passage, leur différence avec «les branchages bizarres des pins de Tarare ${ }^{22}$ ", la petite ville du Rhône où Vietty vécut quelques années et où il mourut. Il constate aussi que le pin "caractéristique de l'Isthme [de Corinthe] a la forme des pins d'Amplepuis ${ }^{23}$ ", localité voisine de Tarare où Vietty naquit en 1787. Enfin, à Épidaure, l'explorateur découvre à terre "une statue de grande proportion, sans tête ", de style " ancien et provincial »: «C'est, écrit-il, une nymphe couchée dans une attitude analogue à celle de ma Nymphe de la Seine. J'ai reconnu ici mon intention de draperie tombante et coulante - le coussin, le socle à losanges sont remarquables ${ }^{24}$. » Le nom et l'évocation de la statue correspondent à une Nymphe de la Seine qui est une des rares statues conservées de Vietty ${ }^{25}$ (fig. 3).

La somme de ces indices nous parait suffisante pour affirmer que les manuscrits retrouvés font partie des «trente-trois carnets de voyage » contenant les notes prises par Jean-Baptiste Vietty au cours de ses explorations scientifiques en Grèce.

\section{Le projet de publication de Vietty sur la Grèce (I 829-I842)}

L'inventaire des manuscrits de Vietty réalisé après sa mort précise que tous les documents ont été " paraphés par le notaire sur la couverture 26 ». Cette numérotation dut être inscrite sans considération du contenu des manuscrits puisque les deux carnets portent les numéros I 2 et 24 sur la couverture intérieure alors que le récit du carnet 24 (juillet-septembre I 829: de Argos à Salamine) précède immédiatement celui du I 2 (septembre-novembre I 829 : de Salamine à Athènes). La contribution exacte de Vietty à l'Expédition est difficile à établir : s'il quitta les autres membres de la section d'archéologie ${ }^{27}$ dès le début de l'Expédition pour poursuivre ses recherches en solitaire, il semble avoir retrouvé ses compagnons au cours de l'été I 829, comme le suggèrent des remarques amères sur ses «chefs » et certaines de

22. Carnet I 2, p. 25 ; carnet I2, p. 83 ; carnet 24, p. I IO.

23. Carnet 24, p. I I I.

24. Carnet i 2, p. 77 .

25. Cette statue sur socle, allégorie de la Seine, représente une femme couronnée de fleurs dans une draperie tombante. Commandée par la ville de Lyon, elle fut exposée au Salon des artistes français de Paris en I 827 et acquise par le musée des Beaux-Arts de Lyon en I833. Voir A. JAL, Esquisses, croquis, pochades sur le salon de I827, Paris, I 828, p. 47 I : «Vous serez charmé aussi d'avoir une figure de M. Vietty, auteur, cette année, d'une Nymphe de la Seine, que j'estime beaucoup. M. Vietty est un homme modeste, timide, d'un talent très distingué ; il n'est pas écrivain moins judicieux qu'artiste habile. »

26. Voir n. I 2.

27. Voir infra. 


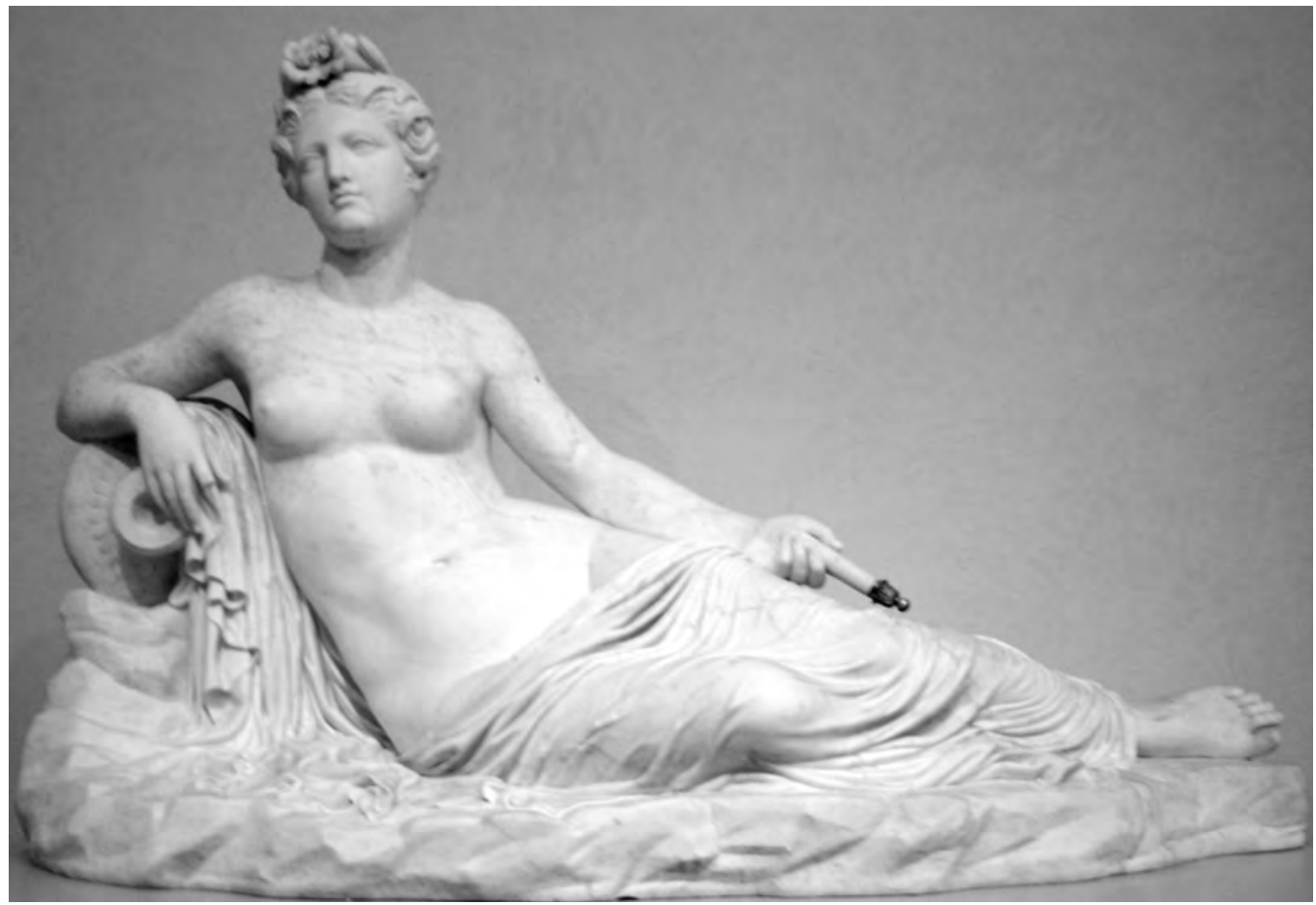

Fig. 3. - Jean-Baptiste Vietty, Nymphe de la Seine (I827) (Musée des Beaux-Arts de Lyon, cl. S. Gioanni).

leurs décisions ${ }^{28}$. À la fin de la même année, lorsque les membres de l'Expédition reçurent l'ordre de rentrer en France, Vietty décida de continuer ses recherches en Grèce où il vécut jusqu'à l'été $\mathrm{I} 83 \mathrm{I}$ dans des conditions matérielles extrêmement difficiles.

De retour en France en août I 83 1 , il soumit ses notes de travail au jugement de l'Institut pour une évaluation de ses recherches. Après avis favorable, le ministère de l'Intérieur chargea Vietty de rédiger un ouvrage qui résumât l'ensemble de ses découvertes, en lui allouant une bourse pendant trois ans. Au cours de cette période, les volumes dirigés par Abel Blouet et l'ouvrage sur la Grèce publié par Edgar

28. Carnet I2, p. 62 : « [À Égine,] il existe un dessin fait avant les travaux de terrassement. On l'a communiqué à nos chefs qui ont jugé ce propos de [illisible], ainsi que les notes de l'Institut et tant d'autres choses!» 
Quinet ${ }^{29}$, ancien membre de la section d'archéologie, obligèrent Vietty à concevoir un projet plus large, «un ouvrage nouveau sur la vieille Grèce, mère de l'Europe $^{30}$ » : s'il avait été « utile à la Commission en retrouvant des villes, des monuments jadis célèbres et restés inconnus des voyageurs depuis Pausanias ${ }^{31}$, [il tâcherait] de l'être plus encore en expliquant la savante théorie, émanée des origines des choses, qui a inspiré et dirigé leur construction ${ }^{32} »$. Malheureusement, la bourse se termina avant que le savant n'ait publié son œuvre. Les quatre lettres de Vietty essayant d'expliquer son retard et demandant au ministre de l'Intérieur de proroger «son modeste honoraire 33 » n'eurent aucun effet sur les autorités de tutelle qui exigeaient la publication immédiate de ses travaux. Retardé par l'ampleur de son nouveau projet et sans doute affaibli par ses conditions d'existence, le sculpteur

29. E. QUINET, La Grèce moderne, op. cit. (n. I s). Quinet publia son ouvrage dès i 830 chez F. G. Levrault alors que Vietty travaillait encore en Grèce. Celui-ci garda une profonde rancune contre son ami qui avait dû rentrer en France, malade, trois mois après son arrivée en Grèce. La confiance entre les deux hommes était suffisamment grande, en Grèce, pour qu'ils décident de se séparer du reste des autres membres de la section d'archéologie dans laquelle régnait un certain amateurisme: voir lettre de J.-B. Vietty à E. Quinet, BNF, n. acq. fr. I 5510, fol. 229-230: « [Paris,] 6 mars I 832. Dear friend, Je désirais beaucoup vous voir. J'ai même été sur le point d'aller à Charolles. Mais après une fièvre de cinq mois j'avais hâte d'arriver dans la prostituée Babylone moderne, plus polluée que l'ancienne ou du moins plus peuplée de filous et de charlatans. J'aurais été encore plus content de votre missive exiguë si elle n'était pas trop dans le sens des $\varepsilon ̋ \pi \varepsilon \alpha \pi \tau \varepsilon \rho c_{\varepsilon} \varepsilon \tau \alpha \alpha$ du vieil aveugle. Je ne vous remercie pas d'avoir dit ce que vous pensiez de votre compagnon de voyage (je pourrais dire seul compagnon, sans nulle vanité) dans le pays... comment faut-il l'appeler ? dorien, comme on dit en France. J'ai dit aussi dans tout notre horizon ce que je pensais de vous. Il parait que vous désirez savoir de moi ce que j'ai dit de vous ; je vous le dirai tout naïvement : j'ai dit que vous êtes un penseur, un écrivain de génie, mais que vous avez esquissé seulement votre Voyage en Grèce. Vous savez tout cela. [...] Que n'êtes-vous dans l'infâme Lutèce ? Nous eussions pu, réunis, opposer une force suffisante contre les intrigues de la cabale. Il faut que moi chétif je lutte seul contre un régiment d'aristocrates plébéiens. J'attends, après des mois, qu'on daigne examiner pendant quelques heures un travail de près de trois ans. Et delenda Lutetia! Faites-moi le plaisir de m’indiquer votre libraire à Paris. Je désire un ex. re de votre ouvrage sur la Grèce pour moi, et un autre pour un vénérable immortel, ou non, de l'Institut. Votre ami, E. Vietty " (lettre citée dans E. QUINET, Journal de Voyage, "Lettres et documents inédits », I984, p. 46046I).

30. Archives nationales, F 2 I $545:$ Lyon, 24 décembre I 835 , lettre de Vietty au ministre de l'Intérieur. 3 I. Sur le rôle de Pausanias dans l'historiographie de la Grèce, voir Pausanias Historien, O. REvERDIN et B. GRANGE éd., Genève (Entretiens sur l'Antiquité classique, 4I), I996, 353 p. ; en particulier Y. LAFOND, "Pausanias et l'histoire du Péloponnèse depuis la conquête romaine », p. I67-205.

32. Archives nationales, F 2 I 545 : la lecture des carnets de I 829 montre que ce projet était déjà au cœur des investigations de Vietty durant son séjour en Grèce (voir par exemple carnet 24, p. I03 et I49).

33. Ibid. : une lettre sans date et trois lettres du 28 mai I 835, 24 juin et 24 décembre ; voir par exemple «Villefranche, 24 juin I 835 : Mes collègues ont presque achevé leur publication. Que V. Excellence me permette de lui exposer la situation respective d'eux et de moi : ces Messieurs n'ont pas voyagé pendant un an dans la Grèce ; je l'ai parcourue durant plus de trois années : donc, je dois avoir plus de matériaux à rédiger ; ils ont plusieurs collaborateurs. La Section d'archéologie exige spécialement beaucoup de recherches épineuses ; ne recevant que la moitié de leur traitement, je n'ai pu me faire aider dans mes propres travaux, d'autant que j'ai voyagé pendant plus de deux ans à mes frais. » 
lyonnais vécut alors de quelques commandes et de la générosité de ses amis, essentiellement le sculpteur Lortet, le juge Peyré, magistrat à Villefranche, et le souspréfet du Rhône Sylvain Blot. Il dut se résoudre aussi à déposer une partie de ses manuscrits « chez divers hôteliers et limonadiers en nantissement du prix des fournitures qui lui avaient été faites $34 »$. Finalement, Jean-Baptiste Vietty mourut le 3 I janvier I 842 dans une grande misère sans avoir publié la moindre page de ses recherches en Morée.

3. "L'affaire Vietty " (I843-I858)

Le géologue Virlet d'Aoust, qui l'avait côtoyé durant l'Expédition, fut le premier à alerter le ministère sur le sort de ses manuscrits et sur leur intérêt scientifique 35 :

«Paris, Io avril i 843 .

Monsieur le Ministre de l'Intérieur,

L'un des plus modestes et des plus savants membres de la Commission scientifique de Morée, mon collègue et ami Vietty, sculpteur distingué, est mort depuis plusieurs mois à Tarare, où il poursuivait ses recherches sur l'archéologie de la Grèce, à la vérité sur des bases tellement larges, qu'avec une vie plus laborieuse que la sienne et avec plus de moyens de recherches qu'il n'en avait dans le département du Rhône, il aurait eu de la peine à y suffire. Néanmoins connaissant la manière toute consciencieuse d'opérer de Vietty, que j'ai eu plusieurs fois l'occasion d'aider et d'accompagner dans ses recherches, et sachant avec quels soins minutieux il avait étudié plusieurs parties peu connues de la Morée et particulièrement la Laconie et Sparte, dont il a, on peut dire, interrogé chaque pierre et où il a su retrouver la plupart des monuments indiqués et décrits par Pausanias, j'ai eu peur en apprenant sa mort prématurée que tous ses matériaux ne se perdissent pour la science; je me suis en conséquence rendu tout exprès à Tarare pour savoir ce qu'ils étaient devenus. Là, j'ai appris que fort heureusement le juge de paix, Mr. Denave, homme fort reconnu, aimable et fort instruit et qui portait le plus vif intérêt à Vietty, avait dans l'intérêt de la science et du gouvernement fait apposer les scellés sur ceux de ses papiers et médailles déposés chez une parente qui, dans les derniers temps de sa vie, le nourrissait à l'aide d'un modique salaire ; qu'il était mort dans une grande misère et en refusant avec fierté et à la manière du Chatterton de Mr de Vigny, les offres obligeantes que ne cessaient de lui faire les personnes les plus éminentes du pays, qui avaient su apprécier et l'étendue et la variété de ses connaissances et les bizarreries de son esprit devenu inquiet et soucieux... J'ai appris enfin qu'il laissait tant à Lyon qu'à Villefranche et à Tarare pour 6 à 7000 francs de dettes et qu'une partie de ses notes et manuscrits se trouvaient encore entre les mains

34. Archives du cabinet des Médailles, i I AMC 23 ; le juge Peyré cite le nom de trois créanciers : le sieur Rozier, aubergiste à Pimbauchain ( 100 F), le sieur Gay, limonadier à Tarare $(8 \circ \mathrm{F})$ et le sieur Viornery, aubergiste à Villefranche (200 F).

35. Archives nationales, F 2 I 545. 
de quelques créanciers, où ils sont restés en nantissement mais où ils sont en sûreté. J'ai conféré à ce sujet avec M. le sous-Préfet et M. Peyré juge, à Villefranche, tous deux amis de Vietty et Mr. Denave m'a affirmé qu'avec i 800 francs ou 2000 francs au plus, on parviendrait facilement à désintéresser en partie les créanciers et à réunir tous les matériaux épars à Villefranche, à Tarare et à Lyon. Plein de confiance en votre sollicitude éclairée, je viens prier votre Excellence de vouloir bien accorder en conséquence aux autorités de Villefranche ou de Tarare qui ont fait elles-mêmes les frais des obsèques de notre malheureux collègue la somme jugée indispensable pour traiter avec les créanciers détenteurs de ses manuscrits et m'autoriser personnellement et de concert avec les autorités locales, à recueillir pour les conserver à la science des documents archéologiques que la Commission de l'Institut avait, tels qu'ils étaient alors, jugés assez importants pour demander le renvoi en Grèce de Vietty qu'elle considérait à juste titre comme l'homme le plus capable pour ce genre de recherche. [...].

Théodore Virlet d'Aoust,

géologue, ancien membre de la section d'histoire naturelle de l'Expédition de Morée. »

La requête de Virlet d'Aoust fut relayée, entre i 843 et I 847 , par les correspondances de diverses autorités (le maire de Lyon, le sous-préfet du Rhône, le directeur des Beaux-Arts) conservées aux Archives nationales dans une chemise intitulée "l'Affaire Vietty » ${ }^{36}$. Le juge Peyré, nommé dépositaire judiciaire des manuscrits au nom de l'État ${ }^{37}$, dressa un inventaire précis des documents de Vietty, des documents sous scellés et des manuscrits épars qu'il finit par racheter lui-même ${ }^{38}$. En juillet

36. Archives nationales, F 2 I 545 . Par exemple la lettre du maire de Lyon au ministre de l'intérieur du 4 mai I 845 : "Monsieur le Ministre, Il y a précisément un an que M. le Préfet du Rhône appelait l'attention de votre Excellence sur les manuscrits laissés par Vietty au moment de sa mort et mis en gage chez quelquesuns des fournisseurs de ce savant tombé seul dans une misère profonde. Une modique somme de I Ioo francs est nécessaire pour retirer ces manuscrits qui sont en très grand nombre et que les amis de Vietty regardent comme très précieux. Veuillez donc, Monsieur le Ministre, donner des ordres pour que cette modique somme soit mise à la disposition de M. le Préfet afin que ces manuscrits soient délivrés et restitués à votre ministère à qui ils appartiennent. Le maire de Lyon. »

37. Ibid., lettre du maire de Lyon au ministre de l'Intérieur du 24 mai I 847 : «Monsieur le Ministre, [...] Il est bien temps que cette affaire reçoive enfin une résolution définitive; M. Peyré, membre du conseil général et juge au tribunal de Villefranche a été nommé dépositaire judiciaire, au nom de l'État, d'une partie des manuscrits de Vietty ; il faut bien qu'il soit mis en mesure de rendre compte de son mandat et de racheter les manuscrits qui restent épars. Permettez moi, Monsieur le Ministre, d'espérer que cette affaire ne subira pas de nouvelles lenteurs [...] Le maire de Lyon. »

38. Voir n. I2, archives du cabinet des médailles, i I AMC 23, inventaire des manuscrits de Vietty: « $\mathrm{I}^{\circ} 37$ cahiers contenant partie des études de l'auteur relatives soit à un grand travail de théorie où il avait entrepris de fondre toutes ses idées sur la civilisation et l'art grec $[\ldots] ; 2^{\circ} 9$ liasses ou cahiers de travaux plus avancés et de rédaction définitive $; 3^{\circ} 23$ liasses de notes ou extraits de lecture $; 4^{\circ} 33$ carnets de voyage dont la plus grande partie paraît contenir les notes prises sur les lieux mêmes et pendant le cours des explorations scientifiques de l'auteur ; $5^{\circ}$ Enfin, 9 cahiers contenant les dessins originaux pris à la vue des monuments ou des contrées qu'il s'agissait de décrire; dessins qui nous ont paru extrêmement remarquables et empreints d'une éclatante couleur de vérité locale. Total, cent onze liasses, carnets ou cahiers tous paraphés par le notaire sur la couverture ou l'enveloppe. Quant aux cent sept médailles grecques qui sont en mon pouvoir, elles ont été renfermées dans un sac de toile sur lequel M. le Juge de paix a placé les scellés. » 
I 848, le magistrat informa les frères de Vietty que le ministère s'était enfin porté acquéreur de l'ensemble des manuscrits. Malgré les lenteurs de l'administration, il espérait que ceux-ci fussent « remis par le Ministre en des mains assez habiles et assez consciencieuses pour en faire sortir toute la gloire qui en revient à [leur] frère 39 ». Mais « l'Affaire Vietty » ne faisait que commencer.

Neuf ans plus tard, MM. Blot et Peyré se rendirent en personne au ministère de l'Intérieur, à Paris, pour consulter les documents de Vietty dont la bonne réception est attestée par un certificat. Mais à leur grande surprise, ils furent incapables de retrouver les manuscrits dont le transfert à Paris avait peut-être été perturbé par le contexte politique de l'année I 848 et les désordres administratifs qui s'en suivirent. Le 29 juillet I 857 , ils firent savoir à M. Chabouillet, membre du cabinet des Médailles de la Bibliothèque nationale, que leur recherche était restée vaine et lui remirent des documents destinés à faciliter ses investigations ${ }^{40}$. Plusieurs savants alertèrent la communauté scientifique en évoquant «l'affaire » devant l'Académie des inscriptions et belleslettres. Au cours de la séance du I 2 mars I 858, le président Philippe Le Bas exprima son souhait « qu'on ne laisse pas ravir la priorité des documents et des observations de Vietty par des savants étrangers ${ }^{4 \mathrm{I}}{ }^{\prime}$. Charles Lenormant, membre de l'Expédition d’Égypte qui avait rejoint les archéologues français en Grèce en i 829, raconta qu’il avait « eu lui-même l'occasion d'éprouver sa sagacité et son savoir » et que «ce fut un malheur, pour l'ouvrage de Morée, de manquer des documents qu'aurait pu fournir cet ingénieux et savant voyageur ${ }^{42}{ }^{2}$. Les Comptes rendus de séances de l'année i 858

39. Lettre citée par L. Charvet, "Jean-Baptiste Vietty ", Réunion des Sociétés des Beaux-Arts, 35 , I9I I, p. 238 : «Villefranche, le 30 juillet I 848. Messieurs, L'affaire relative aux papiers de votre frère est enfin terminée et vous avez dû recevoir ces jours-ci la signification du jugement. Vos frais de justice ont été mis à la charge de l'Etat... Je me réjouis, Messieurs, que cette affaire soit enfin terminée au gré du désir que vous m'en avez souvent manifesté et j'espère que les manuscrits et médailles seront remis par le Ministre en des mains assez habiles et assez consciencieuses pour en faire sortir toute la gloire qui en revient à votre frère. Agréez, etc. Peyré, ancien magistrat à Villefranche (Rhône). »

40. Archives du cabinet des Médailles, I I AMC 23 (voir note I 2 ) : « [...] M. Sylvain Blot fait connaître à M. Chabouillet que le 29 juillet I 857, en suite d'une recherche faite par lui, de concert avec M. Peyré, au ministère de l'Intérieur, un certificat lui fut délivré par M. de la Peyrée, chef du bureau des renseignements, constatant la réception des manuscrits, médailles et dessins précités au ministère de l'Intérieur vers la fin de I 848, lequel certificat fut remis le même jour par M. Peyré à $\mathrm{M}^{\mathrm{me}}$ Hortense Cornu en vue de continuer la recherche commencée. M. Blot, sur la demande de l'Académie des inscriptions et belles-lettres, lui a communiqué, depuis la dite époque, un volume contenant la correspondance qu'il a eue avec feu Vietty à partir de son retour en Grèce jusqu'au moment de sa mort ainsi que les correspondances administratives et ministérielles ayant trait aux ouvrages du savant helléniste [...]. Un carnet renfermant des notes explicatives de Vietty sur la pensée de son ouvrage applicable aux mythes religieux de l'Antiquité a été également communiqué par M. Blot à l'Institut à titre de renseignement. Lorsque Monsieur Chabouillet aura utilisé les documents ci-contre, dans l'intérêt de la découverte des ouvrages de feu Vietty, M. Blot le prie de vouloir bien les lui restituer. "

4I. CRAI, I 858 , p. 52.

42. Ibid. 
célèbrent à plusieurs reprises les mérites de Vietty, « une des plus remarquables individualités scientifiques et artistiques de notre époque 43 », qui avait « reconnu le premier le temple d'Héra à Argos, dont les Allemands revendiquent à tort la découverte 44 ». Ainsi, le 4 juin et le 24 septembre i 858 , l'Académie demanda officiellement au ministère de l'Intérieur la communication des manuscrits de feu Vietty ${ }^{45}$. Ces requêtes de l'Institut, comme les recherches de Léon Charvet un demi-siècle plus tard, n'aboutirent à aucun résultat et, pour une raison encore inconnue, la totalité des documents de Vietty concernant la Morée demeure introuvable depuis cent cinquante ans, à l'exception des deux carnets retrouvés.

\section{QUELQUeS PISTES DE LECTURE}

\section{Un témoignage sur l'Expédition scientifique de Morée}

Correspondant à cinq mois de travail en Grèce, de juillet à novembre I 829, les carnets retrouvés représentent une source directe sur l'Expédition scientifique de Morée qui dura neuf mois, de mars à décembre I 829. Ils révèlent d'abord l'organisation défaillante, ou pour le moins obscure, de la section d'archéologie qui suscitait les sarcasmes des autres membres de l'Expédition ${ }^{4}$. Dès leur arrivée en Grèce, Edgar Quinet et Jean-Baptiste Vietty, qui appartenaient à la section d'archéologie,

43. Ibid., p. I07, n. I.

44. Ibid., p. 52, n. I.

45. Mémoires de l'Institut impérial de France. Académie des inscriptions et belles-lettres, t. XXIII/I, I 868, p. I68: "Communication demandée des manuscrits de feu Vietty. Dans la séance du I 2 mars [I 858], l'Académie, sur proposition de M. Ph. Le Bas, son président, décida qu'il serait écrit à M. le ministre de l'Intérieur et à M. le ministre d'État pour obtenir communication des manuscrits de feu Vietty, statuaire attaché à la Commission de Morée et versé dans la connaissance des langues et des monuments antiques ; ces manuscrits paraissent avoir une certaine importance. À cette occasion, M. Sylvain Blot, ancien préfet, offrit et transmit un volume de lettres à lui écrites par Vietty pendant son séjour en Orient, ainsi qu'un carnet de notes (séance du 4 juin). Sur une demande itérative de l'Académie, M. le Ministre de l'Intérieur la renvoya devant le ministère d'État, saisi par lui de l'affaire et dépositaire des papiers de Vietty, à la direction des Beaux-Arts (séance du 24 septembre) ». L'intérêt de Ph. Le Bas pour les manuscrits de Vietty s'explique par les propres recherches de l'académicien qui commenta les inscriptions recueillies par l'Expédition de Morée et qui se rendit lui-même en Grèce de I 843 à I 846 (voir Ph. LE BAS, Monuments d'Antiquité figurée recueillis en Grèce par la Commission de Morée, Paris, I835-I839; Voyage archéologique en Grèce et en Asie Mineure fait par ordre du gouvernement français pendant les années I 843 et I 844 , Paris, I 848).

46. Lettre du baron Cuvier, membre de la section de sciences physiques ( I 5 avril i 829) : « Ma section est toujours compacte et travaille. Malheureusement il n'en est pas de même de celle d'archéologie. M. Lenormant, arrivé d'Égypte, s'est trouvé (à 25 ans) humilié d'être sous les ordres de M. Dubois (qui en a 50) et a déclaré qu'il était pour son compte, afin de pouvoir correspondre avec le Globe. Un M. Schinas, Grec, et un M. Quinet, philosophe (que je crois fou) sont partis de leur côté, de sorte que ce pauvre M. Dubois reste à peu près seul avec un peintre (Trézel) qui est précisément devenu aveugle en arrivant et le jeune Amaury-Duval. La section d'architecture a aussi une sorte de fou, nommé Vietty, qui court seul sans qu’on sache ce qu'il fait » (voir E. QUINET, Journal, notes complémentaires, n. I I 8, p. 290-29I). 
avaient émis des réserves sur certains condisciples qu'ils considéraient comme des « dilettantes ». Vietty l'écrit ouvertement à Quinet quelques années plus tard:

"Vous vous rappelez que lorsque nous voulûmes quitter nos infirmes camarades pour voyager ensemble, je vous quittai lorsque j'entrevis que vous vouliez parcourir la Grèce comme vous venez de m'écrire. Tel est exactement ce que j'ai dit de vous, beau sire, et de plus que vous avez une mémoire prodigieuse et une grande érudition philologique. Si ce que vous pensez de votre féal est aussi véritable que ce que je pense de vous, qu'on s'émerveille de voir Bory de Saint-Vincent, Blouet et compagnie, gens dont aucun ne sait l'orthographe, imprimer au nom du gouvernement un ouvrage sur la Grèce, tandis que vous et moi, qui avons les mêmes droits, nous sommes rejetés. Circulatores 47 ! Ce fait, s'il était divulgué, passerait pour un chef-d'œuvre de jonglerie, même à Paris $4^{8}$. »

Les deux hommes avaient rapidement quitté leurs compagnons mais ils avaient poursuivi leurs investigations séparément, sans parvenir à s'entendre sur une méthode et un itinéraire communs. Cette attitude avait inquiété les autres membres de l'Expédition qui, après la grave maladie de Quinet et son retour précipité en France au mois de mai, étaient restés sans nouvelle de Vietty ${ }^{49}$ pendant plusieurs mois. Durant cette période, les difficiles conditions de séjour décimèrent peu à peu la section d'archéologie qui vit aussi partir son chef, Dubois, et finit par se réduire à une seule personne, le peintre Trézel. Celui-ci raconte dans son journal de voyage qu’il dut poursuivre l'exploration en solitaire ${ }^{\circ}$, comme Vietty le faisait déjà depuis plusieurs mois ${ }^{5}$. Il

47. "Charlatans », en latin.

48. Lettre de J.-B. Vietty à E. Quinet, BNF, n. acq. fr. I 55 IO, fol. 229-230 (6 mars I 832).

49. Amaury Duval, Souvenirs (I829-I830), Paris, I885, p. IOI-IO2 : «Vietty, le sculpteur helléniste, avait abandonné la section d'architecture, à laquelle il était attaché [...]. Je ne l'ai jamais revu »; p. 230, extrait d'une lettre (date non déterminée) de M. Fabreguette à Amaury Duval qui avait quitté la Grèce dès le printemps I 829: «Point de nouvelles de Vietty, qui vole de ses propres ailes. Je tremble toujours qu'on ne le trouve mort dans quelque fossé. Quelle tête ! " Après son retour en France, E. Quinet exprime lui aussi son inquiétude sur le sort de Vietty dans une lettre à $\mathrm{M}^{\text {lle }}$ Moré (en octobre I 829) : "Presque tous mes compagnons de voyage ont passé ainsi que moi par de violentes maladies. J'attends ici quelques-uns d'eux qui sont réfugiés dans les environs ou à Lyon. Je suis bien inquiet de l'un des meilleurs avec qui j'étais lié un peu et qu'ils ont été obligés de laisser dans une île presque à l'agonie. C’est Vietty » (voir L. CHARveT, « Jean-Baptiste Vietty ", Réunion des Sociétés des Beaux-Arts, 35, I9I I, p. 2 I7).

50. Journal de voyage de M. Trézel (inédit), BNF, n. acq. fr. I 849 , fol. I $9^{\mathrm{r}}$ (2 I juillet I 829 ) : «Des raisons de santé ayant obligé Messieurs Dubois et Duval de rentrer en France, je continuerai seul le voyage avec les instructions que Monsieur Dubois me laisse par écrit. Il emporte avec lui les dessins que j'ai faits depuis le commencement de notre campagne. »

ऽI. Les carnets contiennent, notamment sur les couvertures intérieures, des informations comptables qui nous renseignent sur les dépenses de Vietty, avec descriptif et prix des objets achetés de juillet à novembre I 829: par exemple, "achat de vases et terres cuites " (carnet I2, p. B) et longue "liste de médailles " (carnet 24 , p. B-C et carnet I 2, p. B-D). L'inventaire des manuscrits de Vietty, réalisé après sa mort, signale la présence de 107 médailles (voir supra n. I2). Le problème des dépenses et, plus largement, des moyens de subsistance de Vietty prit une extrême importance à partir de l'hiver i 829, après l'ordre de rapatriement de l'Expédition, le refus de Vietty de rentrer en France et le vol de ses affaires par son domestique (voir lettre 
semble toutefois que Vietty soit rentré en contact avec d'autres membres de l'Expédition ou qu'il les ait retrouvés en septembre sur l'île d'Égine ${ }^{52}$ où Blouet, Poirot et Ravoisié, membres de la section d'architecture, avaient rejoint Trézel 53 . Il se plaint en effet que ses « chefs » négligent des informations essentielles sur les monuments 54 . Si certaines erreurs sont possibles, les critiques de Vietty et son goût pour la solitudess révèlent surtout qu'il supportait mal son rôle «subalterne » dans l'Expédition :

«Je voulais faire fouiller quelques tombeaux mais la position subalterne dans laquelle on m'a placé en une telle Expédition ne m’en a pas laissé, ni le temps, ni les moyens. J'ajourne donc l'étude que j'avais faite de cette partie si intéressante de l'ancienne histoire ${ }^{56}$.

Les investigations solitaires de Quinet 57 et de Vietty sont d'autant plus intéressantes que leurs itinéraires respectifs, souvent improvisés au gré des circonstances, ne recoupent pas exactement celui des autres membres de l'Expédition. Le parcours de Vietty (fig. 4), connu en partie par les lettres à son ami Lortet ${ }^{58}$, peut être reconstitué à travers les carnets ( ${ }^{\circ} 24$ : Argos, Mycènes, Agios-Basilios, Némée, Corinthe, Sicyone, Corinthe, Calamatia, Mégare, Salamine ; n I 2 : Salamine, Égine, Épidaure, Nauplie [Navarin, Modon, Tripolitza, Argos, Nauplie] 59 , Épidaure, Égine, Éleusis, Athènes).

de Quinet à sa mère, 8 février I 830). Tout en bénéficiant de l'aide de certains amis et d'une mensualité (irrégulière) du gouvernement français, Vietty dut se résoudre, jusqu’à l'été i 83 I, à vendre une partie des objets qu'il avait acquis (voir L. Charvet, "Jean-Baptiste Vietty », Réunion des Sociétés des Beaux-Arts, 35, I9I I, p. 2 I 8-2 I9). Cette attitude n'a rien d'exceptionnel puisque Louis Fauvel, peintre et consul de France de i 802 à $\mathrm{I} 838$, se livrait lui aussi à un commerce d'antiquités qui «doivent avoir constitué sa principale source de revenus » (voir A. ZAMBON, "Fauvel et les vases grecs », Journal des Savants, 2006, p. I4).

52. Journal de voyage de M. Trézel, fol. 3 or (Égine, ro septembre i 829) : " Je dessine d'après une terre cuite appartenant à M. Vietty ; c'est un petit amour avec un chien. »

53. Ibid. (Égine, Is septembre i 829) : "MM. Blouet, Poirot et Ravoisié arrivent de leur voyage aux îles; ils logent avec moi et m'apprennent qu'une grande partie de nos collègues ont été fort malades et que plusieurs étaient retournés en France. »

54. Voir supra, n. 27.

55. Carnet I 2, p. 70 : «On se sent mieux séparé du reste du monde. »

56. Carnet i 2, p. 38 .

57. E. QUINET, La Grèce moderne..., op. cit. (n. I s).

58. Lettres citées par L. Charvet, "Jean-Baptiste Vietty ", Réunion des Sociétés des Beaux-Arts, 35 , I9I I, p. 2 IO et s.

59. Le I ${ }^{\text {er }}$ octobre I 829 , Vietty embarqua dans le port de Nauplie sur « une goélette grecque » qui se rendait à Navarin. Ce voyage autour de « la feuille de platane » que forme le Péloponnèse est l'occasion de décrire le relief accidenté des côtes de Laconie et de Messénie (cap Malée, île de Cythère, mont Taygète, cap Matapan...). Ces quinze pages (carnet I2, p. 9I-I05) sont particulièrement difficiles à lire car Vietty, à court d'encre durant la traversée, rédige l'essentiel au crayon. Le retour vers l'Argolide, de Modon à Nauplie, en passant par Tripolitza, se fit à cheval et à pied. L'itinéraire n’est pas décrit mais seulement indiqué dans un titre, avec renvoi à un « livre de notes » que nous ne connaissons pas (carnet I 2, p. I06: «De Modon à Égine par Tripolitza, Argos, Épidaure [de Modon à Argos, Nauplie, voir le livre de notes]»). Vietty raconte son arrivée à Épidaure « au mois de novembre » (carnet I 2, p. I32). 


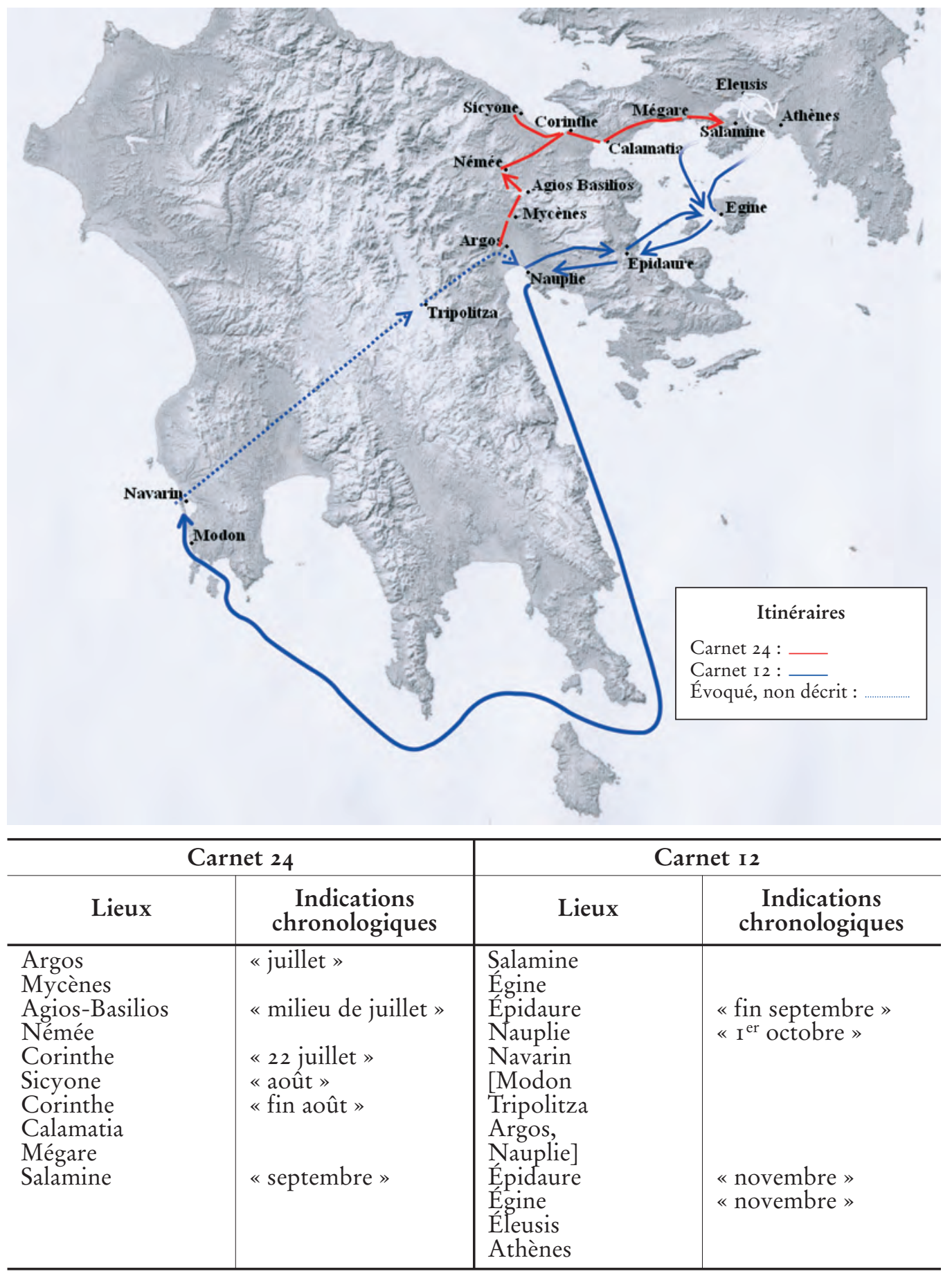

FIG. 4. - Itinéraire de Jean-Baptiste Vietty (juillet-novembre I 829). 
Mais l'intérêt de ces 320 pages manuscrites réside surtout dans la nature des travaux de Vietty : croquis, mesures, inscriptions, analyses des sites. À l'étude des lieux connus se mêle la découverte de constructions antiques et, parfois, le sentiment de découvrir une cité perdue ${ }^{60}$. Les analyses archéologiques font également la place à de nombreux développements sur les paysages, la botanique, la géologie, le climat, les populations locales, l'habitat précaire des réfugiés, les difficiles conditions de vie d'un peuple exposé à la misère et au brigandage dans un pays dévasté par dix années de guerre. Ces carnets n'étaient pas destinés à être publiés en l'état, comme le prouvent les incises qui émaillent le texte : "à vérifier ${ }^{6 \mathrm{I}}$ », «à revoir ${ }^{62}$ ", " ici, description, s'il y a lieu, des coutumes turques ${ }^{63}$ », " ce monument remarquable doit être étudié (nous verrons si j’en aurai le temps) ${ }^{64}$ », «je ne le pense pas mais il faudrait fouiller ${ }^{65}$ ", "il faut étudier encore le temple ${ }^{66}$ », «investigandum est ${ }^{67}$ », etc. Nous avons à faire à «des notes prises sur place ${ }^{68}$ ", l'ébauche d'une publication future. Cette caractéristique, qui explique bon nombre d'approximations, constitue le principal intérêt de ces manuscrits qui reflètent un itinéraire original et qui représentent l'unique travail d'un membre de l'Expédition qui n'ait pas été retouché pour la publication ${ }^{69}$. Ils nous plongent au cour d'un work in progress nourri d'analyses, d'hypothèses $7^{70}$ et de réflexions individuelles ou collectives ${ }^{71}$ qui débouchent sur une étude méthodique.

60. Carnet 24, p. 32 : «Je suis allé sur la montagne d'Agios Basilios sur un faux renseignement de ruines helléniques. Le village sur le revers Ouest d'une haute colline parait être l'emplacement de quelque ville antique. On y trouve des petites tailles employées qui ne semblent pas avoir été taillées depuis la phase chrétienne "; carnet 24, p. 33 : «On voit, à gauche, en plaine, beaucoup de tas de moilons ; il en est qui ont quelques tailles; ils ont l'air anciens et sont couverts de lentisques. Un ruisseau intarissable coule au milieu - une cité, un bourg hellénique, a jadis existé en ce lieu. Je crois voir des murailles sur 2 grandes collines couvertes de lentisques qui bordent cette plaine».

6r. Carnet 24, p. 28.

62. Carnet 24, p. 29.

63. Carnet i 2, p. is6.

64. Carnet I2, p. 35 .

65. Carnet i 2, p. 46.

66. Carnet I 2, p. 70.

67. Carnet 24, p. 43. surplace".

68. Carnet 24, p. I 49-I 50: « cette question très complexe (...) ne peut être traitée dans des notes prises

69. Le Journal de voyage de M. Trézel, inédit (voir n. 46), est un court récit de 35 pages qui fut écrit à Navarin à la fin de l'Expédition et qui retrace le parcours de la section d'archéologie, sans aucune analyse ni aucun relevé archéologique.

70. Carnet 24, p. 40: «il m’a semblé, hier, que les antiques colonnes de Corinthe n'ont pas le profil droit; [note marginale] je ne le crois plus ».

71. Carnet 24, p. 4 : «Il y a moins de caractère lorsque, comme dans cet exemple unique, le parement est travaillé et uni. Ne vaudrait-il pas mieux que les assises fussent régulières ? Nous examinons cette question. En attendant, je pense négativement». 


\section{Une conception extensive de l'archéologie}

Les analyses de Vietty nous permettent de reconstituer globalement sa méthode de travail : $\mathrm{I}^{\circ}$ présentation générale du site (géographique, topographique et historique) $; 2^{\circ}$ description des sols, des roches, de la flore et (parfois) de la faune ; $3^{\circ}$ étude des monuments (mesures, inscriptions, mobilier et interprétation); $4^{\circ}$ commentaires historiques. Au cours de ses recherches, Vietty recueille également de nombreux échantillons dont témoignent les discrètes incises "vid. échantillons ».

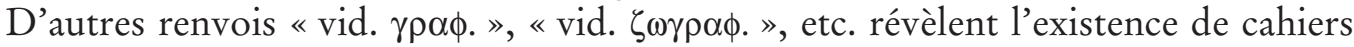
dans lesquels il consignait plus précisément les croquis et les inscriptions. Si ces cahiers sont aujourd'hui perdus, les carnets contiennent eux aussi quelques inscriptions qui se fondent dans le récit ${ }^{72}$ ou, comme dans l'exemple ci-dessous (fig. 5), sont l'objet d'une rapide transcription collée entre deux pages ${ }^{73}$.

La diversité des travaux de Vietty reflète une conception extensive de l'archéologie qui prend aussi en considération l'environnement et l'histoire d'un site. Ils reposent sur une vision globale de la Méditerranée antique qui suppose des compétences linguistiques, philologiques et historiques. Bien qu'appartenant à la section d'archéologie, Vietty prend soin de noter également tout ce qui concerne la physiologie des habitants ${ }^{74}$, leurs coutumes ${ }^{75}$ et leurs activités, notamment agricoles ${ }^{76}$.

72. Par exemple dans l'étude d'Égine, carnet I2, p. 49: «On trouve à côté un cube de marbre blanc sur lequel sont écrits les noms de : Charicléa fille d'Aristocléides; Phoinissa fille d'Eritimos; Callimachos fils de Callippos ? L'inscription paraît complète et le cube, sans mordant, avoir été un piédestal ou socle. »

73. Carnet I 2, p. I I 4 B et p. I I : : On trouve à droite une enceinte elliptique qui était entourée d'un stylobate couronné $[\ldots]$; deux inscriptions : l'une dans l'aire, l'autre vers le pourtour avec le nom d'A $\Sigma \mathrm{K} \Lambda \mathrm{H}-$ $\Pi I \Omega I$ sur une taille courbe. Un couronnement monolithique en marbre d'une très gracieuse et ingénieuse

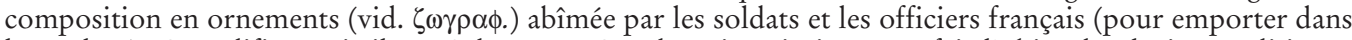
la poche !). Cet édifice était-il un Odéon ?». Ces deux inscriptions ont fait l'objet de plusieurs éditions : I. IG, IV ${ }^{\mathrm{I}}$, Editio minor, Inscriptiones Argolidis, I, F. HILler DE GAETRINGEN, Berlin, I929, n 673, p. I36, Statuae hominum, saec. II p. Chr. ; 2. IG, $\mathrm{IV}^{\mathrm{I}}$, editio minor, $\mathrm{n}^{\circ}$ 249, Arae et bases a. Chr., p. 96.

74. Par exemple sa description des habitants de Corinthe (carnet 24, p. 76) : «Quant aux habitants, j'ai cru voir plusieurs races : la plus générale est une physionomie peu hellénique : tête plus ronde qu'à l'ordinaire, yeux souvent bleus, ou verts et vifs, figure [illisible] de certains hommes de bonne compagnie de nos montagnes, chasseurs et joueurs, bons compagnons, toujours gais, buveurs tels que les $\mathrm{d}[$ illisible] et d'autres dans les monts de Thésée. Je crois que ce sont là les vrais Corinthiens ; $2^{\circ}$ quelques types romains bien reconnaissables à leur tête droite sur un long et large cou, à leur nez aquilin, à leur air sérieux ; $3^{\circ}$ quelques enfants de la beauté sévère hellénique. Les femmes ont toutes le nez un peu court et l'air impudent, agréable et lascif sourire. Il y a-t-il quelques restes italiens ? 2000 ans doivent avoir refait d'autres Corinthiens, sauf peut-être quelques races réfractaires ?»

75. Carnet I2, p. 45: «Les Grecs ont toujours, ainsi que leurs pères, peu d'idée des hiérarchies sociales. Ils ne respectent guère la puissance et la richesse. Ils ne conçoivent pas ce que nous apportons : rang, sang. Voilà le véritable esprit d'égalité, inné chez eux, étranger chez nous, et que nous avons vainement tâché d'implanter en 93. Ils disent encore toi à tout le monde. »

76. Par exemple l'irrigation des campagnes (carnet 24, p. 79), l'évocation des vendanges (carnet 24, p. I 59) et la vente des denrées au bazar (carnet i 2, p. 55). 


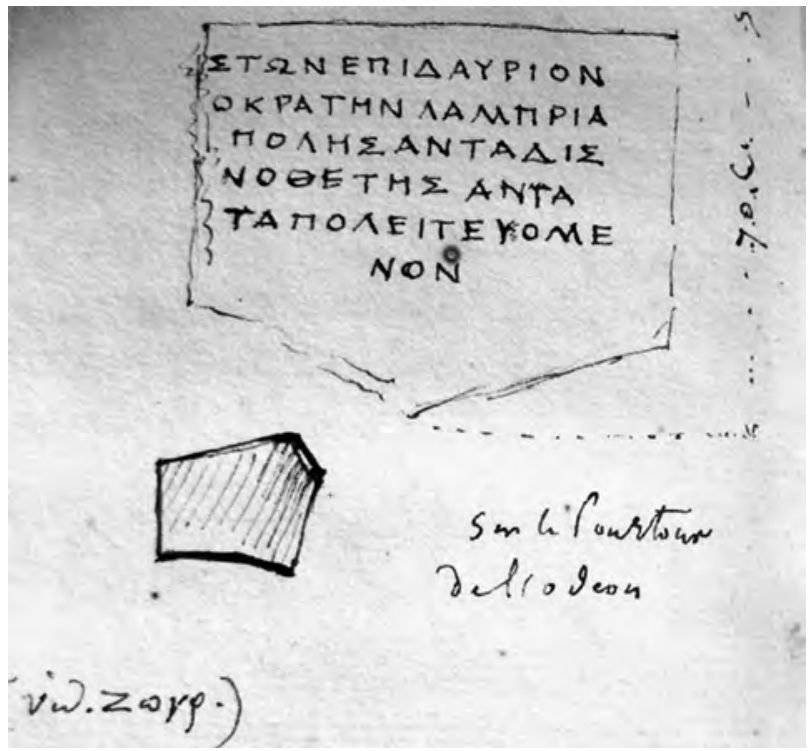

FIG. 5. - Exemple d'inscription trouvée à Épidaure (novembre I 829).

L'objectif était à l'évidence de réunir le plus d'informations possibles sur des lieux que ne traverseraient pas forcément les autres membres de l'Expédition. Conscient des limites de ses compétences dans certains domaines, notamment la botanique, il compense son ignorance par une méthode d'analyse comparative, comme en témoignent ses remarques sur les pins helléniques :

«Ce pin, que j'ai commencé à trouver sur les ravins argileux de Sicyone est l'arbre caractéristique de l'Isthme dont il couvre les plages et les montagnes. Ce n'est ni le pin maritime ni le pin du Nord ni le pin à pignon, ni le pin de L[ord] Weimouth, ni le pin d'Alep ni le pin de Tarare : c'est un pin hellénique. Il tient de tous les pins et ne ressemble à aucun, pas plus au pin-cèdre et -sapin du Taygète qu'aux pins de France et d'Italie. Il n'est point en ombrelle, comme les pins d'Italie, ni pyramidal comme les pins du Nord. A peine a-t-il la physionomie du pin. Il ressemble de loin à l'arbousier. Sa couleur est remarquable : c'est un vert clair, presque jaune, singulière et vive couleur qui s'harmonise, en contrastant avec le vert du buis, du lentisque, le glauque de l'olivier, le vert glacé du caroubier et le ton funéraire du cyprès, du genévrier hellénique (arbre composant la grande végétation de l'Isthme; quelques figuiers). Il ne perd pas toutefois son caractère : on le voit quelquefois prendre une légère forme d'ombrelle, un arrondi comme en Provence. Mais la différence de style général est grande. Quelquefois aussi, il laisse pendre des branches et a la forme des pins d'Amplepuis. Tout cela est rare. Forme, couleur, stature, tout est étonnamment modifié. Il a de 4 à 30 pieds de haut au plus; ses cônes sont mi-maritimes, mi-Amplep[uis] et, deorsum, son feuillage doux, de Lord Weimouth, et son tronc plus tortueux, de même. C'est un pin grec, plus modifié encore dans cette contrée que le peuplier élégant et superbe de Sparte. La dissemblance de la Grèce avec l'Italie se manifeste aussi en ces deux végétaux : je n'ai vu 
en Grèce ni un pin à pignon, ni un peuplier d'Italie. Ce grand et superbe pin à large parasol, à cône statuaire (Italie), est [un] des caractères les plus accentués de l'Italie, et n'est pas grec. En Grèce, les arbres sont des détails. Les monts et les rocs, des formes magistrales. On ne peut écrire le caractère de ces pins : il faut en faire un croquis avec leurs rocs. De quelle espèce les botanistes feront-ils le pin de l'Isthme ${ }^{77}$ ? »

Les analyses architecturales sont elles aussi agrémentées de comparaisons avec des monuments de l'Antiquité romaine ou, plus récents, de la région lyonnaise ${ }^{78}$ et du Nord de la Loire ${ }^{79}$. Les descriptions aboutissent à des commentaires historiques qui laissent entrevoir quelquefois l'ambitieux projet auquel Vietty se consacra dans les dernières années de sa vie : l'étude des origines de la civilisation grecque ${ }^{80}$. Cette préoccupation apparaît nettement dans les ruines des plus anciennes cités grecques dont Vietty cherche à dater les différentes phases de construction ${ }^{8 \mathrm{I}}$. Mais les remarques, parfois confuses, ne sont que des ébauches du projet final. Elles ne sont pas l'objet des recherches en cours, comme Vietty le reconnaît lui-même : "Je ne puis ici que remarquer les faits et réunir au hasard quelques pensées qu'ils me suggèrent. [...] Mais encore une fois, laissons là le discours : non est hic locus ${ }^{82}$. " Le souci documentaire de Vietty, presque exclusif dans les carnets, ne parvient pas toutefois à dissimuler le regard de l'artiste, à la fois peintre et sculpteur, sans cesse ébloui par les trésors de la Grèce ${ }^{83}$.

77. Carnet 24, p. I IO-I I 2.

78. Carnet I 2, p. 90: «Le fort Palamaidi doit être presqu'aussi haut que Fourvière - beaucoup plus rapide, on y monte comme par une échelle. »

79. Carnet I 2, p. I I I : « La couleur sous cet aspect au Nord a quelque chose de gris terne monotone. Comment se fait-il qu'avec tant de différences en tous points, ce premier aspect d'Athènes m'ait rappelé Laon, Chartres, Reims, d'autres villes religieuses de France à colline rocheuse ? ».

80. Sur ce projet, voir n. 30 et 32 .

8 I. Carnet 24, p. I 49 : «Ou les murs de Tirynthe, de Mycènes, Phigalie, etc., etc., sont antérieurs à l'arrivée des Égyptiens, ou postérieurs. Si antérieurs, il n'y a rien à dire, la construction est identique au pays mais alors la civilisation de la Grèce serait plus ancienne qu’on le pense. Si postérieurs, il se présente plusieurs objections ou hypothèses : les Égyptiens ont-ils pu bâtir ou enseigner à bâtir ainsi ? La localité, la nature l'avait-elle emporté en Grèce, en fait d'architecture militaire, sur les habitudes, l'école du pays, si différente, de l'Égypte ? Ou les Grecs, peuple fort et distinct, bientôt après avoir été rassemblés par les orateurs et reçu d'eux les lettres, le culte, la civilisation (la terre hellénique fécondée) auraient-ils fait de tout cela ce qu'ils ont fait des temples égyptiens, de leurs mythes, de leur doctrine religieuse et politique (de leur poésie sans doute) ?».

82. Carnet 24, P. I49-I 50.

83. Le témoignage de Vietty est influencé par le « retour à l'antique » amorcé par Winckelmann dans le second XVIII ${ }^{e}$ siècle qui érige l'art grec en modèle de représentation harmonieuse. Voir É. SALICETO, «Le voyage de la Grèce, un nouveau retour à l'antique ? ", dans Acta Fabula, L'Itinéraire de Paris à Jérusalem de Chateaubriand, publ. sur www.fabula.org. "L'expression "retour à l'antique” désigne explicitement le mouvement amorcé dès le second dix-huitième siècle et théorisé en particulier par l’Allemand Johann Joachim Winckelmann (I7I7-I768), dont l'œuvre aura une importante répercussion en France et dont les théories seront étendues à l'ensemble des arts : Réflexions sur l'imitation des œuvres grecques en peinture et en sculpture (1755) et Histoire de l'art dans l'Antiquité (1764) inaugurent un déplacement de l'art romain à l'art grec comme incarnation de l'essence antique, déplacement géographique qui correspond à un recul historique et donne son essor au mouvement néoclassique. » 


\section{Le regard d'un artiste}

Dans ce pays où même « la lune colore le paysage des couleurs du soleil ${ }^{84}$ », les paysages sont décrits avec des touches de couleurs et une palette de tons expressifs :

«Il faut admirer la couleur de ces monts arides : fond jaunâtre et rougeâtre, roussi par la couleur gris-argent des rochers, sous un ciel d'un bleu presque blanc, teinté de rose $^{85}$. »

Tout au long de son itinéraire, Vietty, tel un peintre, saisit des images et des portraits qui correspondent parfois, si l'on en croît certaines notes marginales, à des dessins perdus: "dessiné chapiteau corinthien et ionique, un petit groupe de 3 femmes ${ }^{86}$ », un visage d'enfant « de grand style hellénique » ${ }^{87}$, une jeune Corinthienne auprès d'une fontaine ${ }^{88}$, la population misérable d'Argos travaillant sur des fouilles ${ }^{89}$, les logements insalubres des réfugiés exsangues ${ }^{90}$, les femmes ipsariotes qui ont le plus élégant costume de la Grèce ${ }^{9 \mathrm{I}}$, un vieillard sourd gouvernant le caïque jusqu'au Pirée ${ }^{92}$, un jardin d'agrumes qui forment un oasis délicieux ${ }^{93}$, le frétillement des serpents dans les broussailles d'Épidaure ${ }^{94}$, une main colossale encastrée dans une maison d'Égine ${ }^{95}$, l'immense incendie dévastant l'Isthme de Corinthe ${ }^{96}$, etc. Le lecteur chemine ainsi, par l'écriture et le dessin (fig. 6), au milieu d'innombrables images « à travers les arbres de Cybèle qui, mêlés à l'olivier sauvage, aux lentisques ou aux caroubiers, forment un continuel bocage qui s'étend sur le flanc des monts et couronnent leur tête de forêt sur ces rocs abrupts qui ressemblent à de hauts remparts et à des tours à demi écroulés 97 ».

\footnotetext{
84. Carnet I 2, p. 45 .

85. Carnet 24, p. I58-I59.

86. Carnet 24, p. 72.

87. Carnet i 2, p. 8.

88. Carnet 24, p. 53 .

89. Carnet 24, p. I 2.

90. Carnet i 2, p. 7.

91. Carnet i2, p. 45 .

92. Carnet I 2, p. I 42.

93. Carnet I 2, p. 88.

94. Carnet I 2, p. I 1 I : «Dans cette promenade, faite au mois de novembre, par un beau soleil, je vis ou j'entendis, en plaine, 8 à io serpents dans les broussailles. Je cherchai à m'emparer de l'un d'eux, pour vérifier la tradition mais ils ne sont plus aussi familiers qu'aux temps des prêtres d'Esculape. »

95. Carnet I 2, p. 50.

96. Carnet 24, p. 105-108.

97. Carnet 24, p. II 5 .
} 


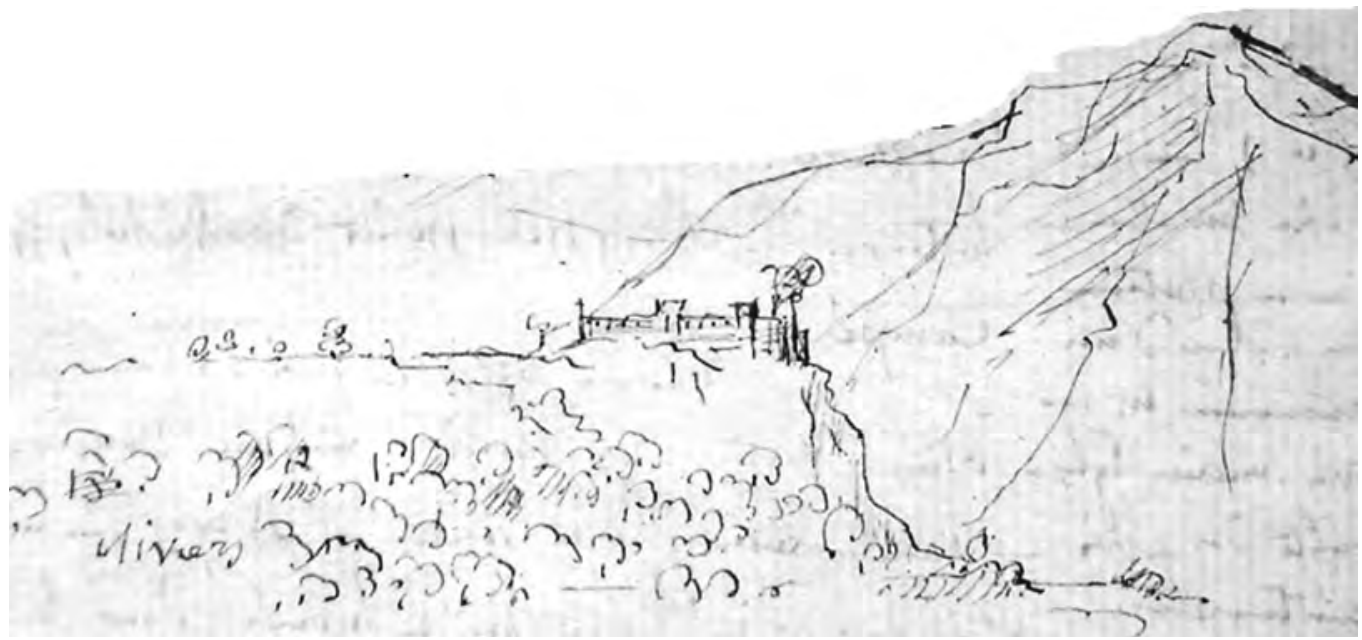

FIG. 6. - Croquis d'une forteresse non identifiée sur la route d'Argos à Épidaure (novembre I 829) ${ }^{98}$.

Le lexique révèle l'intérêt de Vietty pour les formes sculpturales de la nature hellénique, "artiste par excellence 99 " avec ses "paysage[s] de sculpteur ${ }^{100}$ ", ses « amphithéâtre[s] de montagnes ${ }^{101}{ }^{\text {» et ses } ~}$ montagnes $(. .$.$) stylisées { }^{102}$ ».

«Les autres rochers aigus qu'on voit au Nord [d'Athènes] sont d'une forme plus artiste encore, beaucoup plus statuaire que celle de l'Acrocorinthe. C'est exactement le style fort et sévère, pur et concis, hiéroglyphique des pierres gravées et des beaux basreliefs : vrai paysage de sculpteur (l'Acrocorinthe tient un peu du peintre) ${ }^{103}$. »

98. Carnet I2, p. I09-I I0: «Au pied des montagnes, quelle était cette ville sauvage, homérique ? Une I/ 2 lieue plus haut, du même côté, sur une autre montagne dominée par une [montagne] beaucoup plus considérable, est une autre ville (ou fort) plus grande, plus régulière, plus pittoresque, mieux conservée. Longs bois d'oliviers parsemés sur cette colline. Même genre de situation, plus en grand : presqu'île formée par deux rivières dont l'une coule cachée sous les arbustes. La route d'Argos à Épidaure passe au pied sur l'autre revers. - Encore une autre ville inconnue! Serait-ce Midéa ? Je n'ai pas le temps d'y monter».

99. Carnet I 2, p. 38.

I00. Carnet I2, p. I23.

IоI. Carnet 24, p. 30.

102. Carnet i 2, p. 89.

I03. Carnet i2, p. i 2. 
La sensibilité artistique de Vietty est exacerbée par un enthousiasme sans borne, attisé par les découvertes archéologiques ${ }^{104}$ et par le désir de devancer l'action inexorable du temps ${ }^{105}$. Malgré la difficulté des excursions ${ }^{106}$, cet enthousiasme est également stimulé par l'envie irrésistible de découvrir Athènes. Vietty est comme aspiré par « la ville de Minerve » qui se dérobe derrière les hauteurs de Salamine, apparaît au loin depuis l'île d'Égine ${ }^{107}$ et finit par se livrer toute entière à la fin de l'automne ${ }^{108}$ :

«C'est ainsi que je m'acheminais gradatim vers cette partie exquise de la terre, vers cette ville dont la gloire éternelle est celle de tous les hommes. Le nom d'Athènes respecté par les Romains dans l'orgueil de leur triomphe, par le terrible Sylla victorieux, ce nom sacré, moins grand, peut-être, que celui de la sublime Sparte ; au dessus de celui de la brigande Rome et le premier de tous les noms dans l'histoire de l'esprit humain, Athènes faisait palpiter mon cœur. J'allais la voir!... Dans une heure, à Ambelaki, je verrai Athènes à quatre lieues de distance; ces monts jaloux de Salamine ne me cacheront plus la ville de Minerve $[\ldots]^{109}$. »

L’appétit de connaissance, la joie des découvertes et la quête de la lumière athénienne traversent l'ensemble d'un récit qui est également hanté par le spectacle omniprésent de la désolation. Les membres de l'Expédition sont en effet confrontés en permanence à différentes formes de dévastation, anciennes et contemporaines, qui font de la Grèce un immense champ de ruines.

I04. Par exemple, les restes de statues enfouies à Mégare; voir carnet 24, p. I 38 : «Près du sommet est une église toute bariolée de marbres divers [...] une grande statue sans tête à demi-enfouie qui paraît d'un beau style et qui doit être une muse ; une inscription (vid. $\gamma \rho \alpha \phi$.) disant que ce temple a été consacré aux muses»; p. I 2 : «En remontant sur le revers de la colline je trouvai une statue de femme drapée de grande proportion, couchée sur le ventre, acéphale, mutilée. Mais le bras que je pus voir et le genre de draperie me semblèrent d'un ancien et beau style hellénique. C'est le troisième reste de statue que j’ai vu à Mégare (sans indication). On n’a pas souvent en Grèce ces bonnes fortunes. Les Anglais ne les ont pas aperçues. »

I05. Par exemple, à Mégare, ce «promontoire en roches par assises presque horizontales qui doit s'écrouler bientôt dans les flots : la mer, par un long travail, a scié les assises inférieures et la masse est lézardée perpendiculairement" (carnet 24, p. I I9).

I06. Carnet 24, p. i I7: "La chaîne du Geranion s'étant rapprochée de la mer, forme une énorme berge. Des rocs scabreux dont les pieds sont baignés par les flots. Le sentier, souvent taillé dans la pierre, serpente sur ses flancs. Pour y monter de la plage, il faut se mettre à la mer pour tourner au cap, ou grimper à 50 pieds sur des rocs à pic dont la moitié est lisse comme un lit d'assise. Il fallut décharner le cheval et monter le bagage avec des cordes. Je me hasardai à cette raide excursion et faillis me rompre le cou où nos Grecs allaient, venaient assez aisément avec des fardeaux. "

I07. Carnet I 2, p. 7I.

I08. Carnet I 2, p. I 50-I I I : « Nous avions monté insensiblement depuis la mer, nous montâmes alors, mous franchîmes cette barrière qui nous avait caché le Parthénon : alors je vis Athènes dans Athènes. Le premier coup d'œil me surprit : je n'avais pas imaginé cela : grandeur capitale grecque. Palicarerie civilisée ; vivacité avec tempérance, acropole religieuse en vaisseau, comme la cathédrale de Reims. À l'entour, petits monts modelés comme les rochers des statues ; plans vifs brefs, sans rudesse ni sauvagerie, savants de dessins, beaux d'ensemble et de détails. Loin d'ici la férocité, la fougue du Péloponnèse ! La couleur sous cet aspect au Nord a quelque chose de gris terne monotone [...]. »

ı०9. Carnet I 2, p. 8. 


\section{Le spectacle de la désolation}

a. Le dilettantisme, le pillage et les dégradations

Par sa rigueur et sa sensibilité, Jean-Baptiste Vietty réalise une sorte de compromis entre les exigences scientifiques de la Mission et l'enthousiasme romantique des explorateurs qui parcouraient la Grèce. Avec d'autres chercheurs de son temps, il contribue à définir une nouvelle approche de l'Antiquité grecque qui passe néanmoins par une critique des pratiques antérieures. Par exemple, il ne rate jamais une occasion de se démarquer de ces «voyageurs [qui] n'y voyaient pas clair ${ }^{\text {IIo }}$. Chateaubriand II ${ }^{\text {I }}$ est la cible principale :

«On trouve le lit de l'Inachos (...) orné d'agnus-castus, uniquement. Un pont rompu, de 3 arches le traverse. Ce pont n'a point de parties ou de tailles helléniques. Pas le moindre filet d'eau sur ses galettes desséchés. Chateaubriand n'aurait pu remplir une fiole ${ }^{112}$. »

«Est-ce Chateaubriand ou Pouqueville qui disent n'avoir pas retrouvé [le temple de Neptune à Corinthe] ? Certes, c'est là l'une des plus étranges bévues qu'ait jamais faite aucun voyageur. Quiconque arrivera à Corinthe, ayant lu ce passage, ne peut manquer de faire ce dilemme absolu : ou l'auteur qui rapporte le fait n'a jamais vu cette ville, ou il y est arrivé par une nuit bien noire (chose en Grèce d'une grande rareté) et en est reparti avant le jour ${ }^{113}$. »

L'ironie laisse la place à la colère lorsque Vietty dénonce les pratiques dévastatrices des explorateurs peu scrupuleux. La Grèce est en effet victime, depuis l'Antiquité romaine, de pillages incessants qui ont fini par la vider de ses trésors antiques et qui rendent souvent l'analyse impossible : "Mille fois pillée depuis les Romains jusqu'à nos jours, cette terre si féconde en chefs-d'œuvre est restée nue sauf quelques tombeaux et ses productions inimitables sont entassées dans tous les cabinets de l'Europe ${ }^{\text {II4 }}$. » Les dégradations des voyageurs sur les monuments antiques suscitent elles aussi son indignation :

«Un autre genre de vandalisme, plus stupide encore, peut-être, et surtout plus général, a concouru à défigurer les ruines respectables: la manie des petits esprits (grande majorité de l'esprit humain) d'écrire leurs noms sur les monuments célèbres, a été poussée ici au dernier degré d'extravagance. Presque toutes les pièces du temple

I Io. Carnet 24, p. 73.

I I I. Vietty n'était pas le seul à se moquer du dilettantisme de Chateaubriand : voir M. SÈVE, Les voyageurs français à Argos, Athènes, Paris, I993, p. I4 (Sites et monuments, XI) : " [Il] s'attira d'aigres critiques du médecin Avramiotti qui l'avait hébergé à Argos. Il semble avoir manifesté un intérêt superficiel pour ce qu'il voyait : le premier des touristes. »

I I 2. Carnet 24, p. I6.

I I3. Carnet 24, p. 5i-52. Vietty évoque à nouveau cette anecdote p. 66.

i I4. Carnet i2, p. 5 I. 
entassées dans son enceinte sont entachées de ces noms obscurs, gravés souvent profondément dans la pierre et quelquefois d'un demi-pied de proportion. Allemands, Anglais, Français, etc. tous ont cru devoir apporter leur signature sur le Panhellenion et les Grecs modernes n'ont pas manqué, par imitation, de se signaler de la même manière. Insensés, pauvres gens, idiots, troupe ignorante et rustre, pensez-vous vous illustrer en gravant vos noms indignes sur un monument illustre ? Si cette pierre que vous avez dégradée et profanée est encore longtemps conservée, la postérité saura [que] S... N... étaient des êtres vaniteux, ignorants et ridicules ${ }^{115}$. »

L'irritation de Vietty vise tout particulièrement les Anglais, ces « derniers vandales ${ }^{116}$ », dont il dénonce tour à tour l'impérialisme et les pillages destinés à enrichir les musées londoniens :

«Les Anglais se sont emparé de [Cythère] ainsi que de tant d'autres postes avancés, de tant de clefs. Ils se sont aussi accommodés de Corfou, Zante, Céphalonie, comme ils ont fait des îles de France, etc., etc. On les a laissés faire : ils ont bien fait. Il y a de quoi tomber de son haut mais nos savants diplômés trouvent cela tout naturel et les colossales puissances de l'Europe, ardentes à se guerroyer, ont ainsi laissé jalonner et emprisonner le monde par une poignée de forbans insolents que la France seule a conquis autrefois. Un trait de plus et qui sera signalé dans les anomalies de l'histoire ${ }^{117}$. »

«[Le temple d'Égine] serait demeuré entier sans l'avide et aveugle rapacité des prétendus amateurs ou plutôt marchands anglais. À Égine, par toute la terre, cette race dévorante a exercé ses honteux ravages, fouillant, démolissant, brisant les rares et précieux restes de l'ancienne histoire de l'humanité qui, transposés en pièces dans la sombre Albion, sont déjà ternis et défigurés sous ce[tte] noir[e] atmosphère ${ }^{\mathrm{II} 8}$.»

Cette hostilité à l'égard des Anglais est révélatrice d'un état d'esprit partagé par de nombreuses personnalités françaises. La naissance de l'École française d'Athènes n'est pas sans rapport avec cet antagonisme politique et scientifique : le décret de fondation de l'École, en septembre i 846, est l'aboutissement des efforts conjoints de l'ambassadeur de France en Grèce, Théobald Piscatory, du ministre français de l'Instruction publique, le comte Achille de Salvandy, et du premier ministre grec Iannis Kolettis qui voulaient renforcer la présence de la France et contre-balancer l'influence des Anglais ${ }^{119}$. En revanche, sous la plume de Vietty, l'évocation des Turcs, pourtant ennemis de la Grèce et des puissances occidentales, est beaucoup plus ambiguë : s'il considère que « l'Orient et l'Égypte ont fini par écraser la Grèce et [qu'] Ibrahim a été plus vandale que Genséric ${ }^{\text {I2O }}$ ", il n’hésite pas à souligner la

I I s. Carnet i 2, p. 64-65.

I 16. Carnet I 2, p. 58 .

i I7. Carnet i 2, p. 95 .

I 18. Carnet i2, p. 64.

I I9. Voir R. ÉTIENnE, L'espace grec: iso ans de fouilles de l'École française d'Athènes, Paris, I996; C. Valenti, L'École française d'Athènes, Paris, 2006.

I 20. Carnet 24, p. 53 . 
cordialité des sentinelles turques, sur la route d'Athènes ${ }^{\mathrm{I} 2 \mathrm{I}}$, et l'hospitalité du Bey d'Athènes, Ioussouf :

« Nous fûmes reçus chez lui avec plus d'égard, de cordialité, de délicate hospitalité qu'aucun étranger ne l'a jamais été chez aucun Bey ou Pacha de Paris ; sa table turque était recherchée ; il couchait au milieu de nous. Il nous donna le spectacle de l'exercice de ses délices. - Et les Français venaient de brûler la flotte du Sultan; ils bâtissaient des forts pour ses sujets révoltés; ils étaient venus en armes dans ses provinces $[\ldots]^{122}$. »

b. La guerre, le feu...

La Guerre d'indépendance (I82I-I829) qui venait de se terminer avait provoqué de terribles destructions, en particulier dans les zones habitées. La plupart des villages et des villes n'étaient que champs de ruines, à l'exemple de la ville moderne de Corinthe :

«La ville moderne de Corinthe, maintenant détruite, divisée en plusieurs bourgades séparées par des champs et des jardins bien arrosés, n'était donc pas si misérable que nos voyageurs l'ont fait entendre. Elle était presqu'aussi grande que Tripolitza. Nos voyageurs n'y voyaient pas clair. C'est à présent qu'elle est misérable ainsi que tant d'autres! Mais avant la guerre, c'était une des grandes villes du Péloponnèse ${ }^{123}$. »

Quittant Corinthe sur une vision d'horreur (des rues parsemées d'ossements humains mêlés à des restes d'animaux ${ }^{124}$, Vietty se dirige alors vers Mégare qui offre le spectacle d'une cité fantôme :

"C'était une grande ville que Mégare pour la Grèce. Elle a pu rivaliser avec Athènes en puissance. Au second coup d'œil, je vois toutes les maisons en ruines; toute la ville déserte... J'ai cru être transporté dans les villes de Libye dont les maisons,

I 2 I. Carnet I2, p. I45: «Les Turcs du poste vinrent lentement, le fusil derrière le cou (...) s'embusquer derrière le tertre prolongé qui forme bordure à la plage du port. Ils s'y accroupirent, le bout du fusil en avant. Nous déjeunions sur une chaussée. Après ro minutes de station, ils vinrent tranquillement s'asseoir à nos côtés, mangèrent, burent du rhum et nous laissèrent manier leurs armes ".

I 22. Carnet i 2, p. I55-1 56. Ce récit tranche avec la longue narration d'Abel Blouet qui fut invité lui aussi, avec les membres de sa section, par le Bey Ioussouf. La version « officielle » de l'Expédition distille en effet de nombreuses critiques, évoquant « le repas le plus singulier et le plus malpropre qu'on puisse imaginer », l'attitude des « chefs » qui « s'humiliaient en la présence du bey avec une bassesse inouie » ou le refus du Bey de «les laisser visiter (...) les monuments de la citadelle » (Expédition scientifique de Morée : architecture, sculptures, inscriptions, op. cit. [n. I4], vol. III, p. 62-63).

I 23. Carnet 24, p. 73.

I 24. Carnet 24, p. 77-78: «Dans les murs vides d'arbres comme de citoyens, on ne voit que quelques figuiers solitaires dont l'ombre sert d'asile à l'animal immonde. Le soleil dévore même tes plantes funestes et n'épargne que l'horrible nopal dont l'ombre épaisse n'est accessible qu'aux reptiles. Tes rues sont encombrées des murs à demi-écroulés de tes masures, marquetés des marbres défigurés de tes temples et de tes palais. Elles sont parsemées des ossements exhumés de tes tombes, Turcs, Chrétiens, Romains, Grecs mêlés aux ossements des chiens et des chevaux. Un seul couple de palmiers croissait dans un enclos, les arabes en ont brisé la tête et le tronc de l'un d'eux gît à côté comme un fût de colonne. Superbe Corinthe ! Que restet-il de tant d'édifices élevés dans ta vaste enceinte ?» 
placées au milieu du désert, sont depuis si longtemps, vides d'habitants. Je descendis avec horreur dans cette vaste solitude m'égarant dans le labyrinthe de rues obstruées par les murs écroulés, dans les cours pleines de débris ${ }^{125}$. »

La progression vers Athènes apparaît donc comme une longue traversée de ruines où les noms héroïques du passé se mélangent aux malheurs du présent. Même la découverte de Salamine, dont le nom est étroitement lié à la grandeur athénienne, inspire un sentiment de désolation devant tous ces conflits qui meurtrissent l'Europe depuis l'Antiquité, des guerres Médiques aux boucheries napoléoniennes:

«Le voilà donc le détroit de Salamine dont le nom, comme celui de Marathon, des Thermopyles, a fait le charme de notre jeune imagination [...], le détroit de Salamine qui vit jadis la défaite du grand roi. Voici l'île basse où les Perses réfugiés périrent par la lance athénienne. Je vois la montagne d'où le roi des rois vit fuir les nombreux vaisseaux... Pourquoi toujours la gloire environne-t-elle les lieux qui virent égorger des milliers d'hommes ? Tel est le triste génie de l'humanité. C'est ainsi qu'on va visiter avec respect les champs de Cannes, de Pharsale, d'Austerlitz $[\ldots]^{126}$. »

Cette impression s'explique par le souvenir des combats récents mais aussi par leurs conséquences sur le mode de vie des survivants. Même victorieuse, la Grèce indépendante doit reconstruire un pays dévasté par une "guerre d'extermination $^{127} »$ : les populations réfugiées dans le golfe de Salamine sont victimes du manque de nourriture ${ }^{\mathrm{I} 28}$, des épidémies ${ }^{\mathrm{I} 29}$, des brutalités des palicares désœuvrés ${ }^{\mathrm{I} 30}$ et des incursions imprévisibles des Turcs d'Athènes ${ }^{\text {I3I }}$. Si ces violences sont la preuve irréfutable que «l'homme est né ennemi de l'homme ${ }^{\mathrm{I} 32}$ », les destructions

I 25. Carnet 24, p. I34.

I26. Carnet i 2, p. I6.

I 27. Carnet 24, p. I3.

I 28. Carnet 24, p. I 53 : «Je bus délicieusement de son eau frâiche qu'un vieux Mégarien assis au bord me tira avec sa corde $[\ldots]$ mais je n'avais pas le pain qu'il demandait. »

I 29. Carnet I 2, p. I 34 : «Des mares fangeuses et puantes, réceptacles d'égouts et d'immondices, cause de plus d'une épidémie »; voir aussi carnet 24, p. 60 (le commandant malade); p. I I 4 (le domestique malade), etc.

I 30. Carnet I 2, p. 23-24: «Le lendemain matin, me disposant au départ, je vis fermer soudain toutes les boutiques. Mon jeune homme me vint dire que 3 ou 4 mille palicares allaient arriver et piller amis et ennemis. L'astynome me confirma cette nouvelle. Ayant vu à Mégare ce que savaient faire ces soldats sans discipline, je [illisible] un caïque et partis de suite pour Égine (mon hôte et beaucoup d'habitants en ont fait autant). »

I 3 I. Carnet 24, p. I $26:$ : Je montai sur une éminence pour contempler, à une demi-lieue, le croissantthéâtre non adossé de Mégare, ville encore assez grande mais, dit-on en ce moment, absolument désertée, les Turcs d'Athènes y faisant des excursions. Nous avions appris [...] qu'ils avaient pillé Éleusis, que les Palicares du port de Mégare s'emparaient de tous les chevaux ».

I 32. Carnet 24, p. $54:$ :L'homme est né ennemi de l'homme. Ceux qui disent le contraire sont des sots ou des charlatans. [...] Et c'est pourquoi l'amitié est l'héroïsme le plus noble et qui honore le plus l'espèce humaine. » 
ne se limitent pas aux ravages de la guerre. Dans l'été brûlant ${ }^{133}$ de l'année I 829 , l'Isthme de Corinthe est en effet la proie de violents incendies de forêt :

«Je trouvai le lendemain soir la grande table de l'Isthme et les monts de la

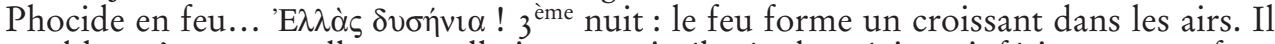
semble qu'une nouvelle constellation se soit élevée des régions inférieures : ces feux semblent vouloir rivaliser avec les étoiles !! L'Isthme entière serait-elle embrasée par un feu de berger ? J'ai écrit les ruines de Sicyone sur les ruines de Corinthe à la clarté de l'incendie de l'Isthme ${ }^{134}$. »

Qu'elles soient causées par les vandales, par les siècles ou par les flammes, les destructions délivrent finalement une image paradoxale de la Grèce où le sublime semble consubstantiel au néant. Ces évocations contribuent à l'originalité des carnets de Vietty qui constituent un double témoignage sur l'état des sites antiques en I 829 et sur la Grèce contemporaine durant les premiers mois de son indépendance.

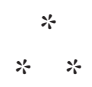

Notre brève étude comprenait deux volets radicalement distincts : $\mathrm{I}^{\circ}$ l'identification des carnets retrouvés ; $2^{\circ}$ la présentation des travaux d'un archéologue de l'Expédition de Morée. Si l'analyse des documents permet d'attribuer les carnets à Jean-Baptiste Vietty, il ne faut pas oublier qu'ils représentent une infime partie de ses manuscrits qui demeurent pour l'heure introuvables. Leur disparition, une quinzaine d'années après la mort du savant, reste inexpliquée et nous espérons que cette étude permettra de rouvrir « l'affaire Vietty » et de retrouver les documents perdus. En ce qui concerne le contenu des manuscrits, il reste beaucoup à faire, là aussi, pour comprendre le rôle exact de Vietty dans l'Expédition et pour apprécier l'intérêt de ses notes. Nous avons pensé que la publication d'un extrait permettrait aux historiens d'évaluer plus précisément l'apport documentaire de ces manuscrits et de déterminer si les deux carnets - en attendant peut-être d'autres découvertes - méritent d'être édités dans leur intégralité.

\section{Stéphane GIOANNI}

I33. Carnet 24, p. I I9: "J'éprouvai à la fin d'août au plus haut degré ces températures que je n'avais jamais ressenties. Sans marcher vite, au repos, les rayons solaires faisaient ruisseler la sueur que j'essuyais à chaque instant. On ne pouvait tenir deux secondes la main sur les rochers. »

I34. Carnet 24, p. I05. 


\section{ANNEXE \\ EXTRAIT DES CARNETS DE JEAN-BAPTISTE VIETTY}

L'étude d'Égine (carnet I2, p. 27-7I), réalisée en septembre I 829, offre un exemple de la méthode de Vietty. La difficulté à déchiffrer ses notes de travail ne nous a pas permis d'éviter les blancs ou les approximations que nous signalons par les indications [illisible] ou [vérifier]. Les passages en italique correspondent aux mots soulignés par l'auteur. Nous avons cité entre parenthèses les remarques marginales inscrites en petits caractères sur le bord des pages. Ayant été rédigées en Grèce, ces marginalia contiennent des précisions recueillies par Vietty au cours de son itinéraire mais aucune ne semble correspondre à une relecture des carnets, après son retour en France. En revanche, il ne nous a pas semblé utile de reproduire la totalité des petits croquis, souvent très schématiques, qui accompagnent le récit. Les notes infrapaginales sont de notre fait.

\section{À Égine}

L'île d'Égine ${ }^{\mathrm{I} 35}$, demi-attique, demi-argolique, assez grande pour être indépendante, est située presqu'au centre de la Grèce toute comprise : îles, continent, colonies d'Asie ; le Panbellénion ${ }^{136}$ y fut convenablement placé. Des parties un peu élevées de sa surface, on découvre une grande partie de la terre hellénique. Je vois de ma maisonnette sur la butte aux moulins non loin du temple de Vénus ${ }^{\mathrm{I} 37}$, à l'horizon, l'Hymette et l'Acropole d'Athènes; toute la longueur de l'île de Salamine, la chaîne des monts et la plaine de Mégare; toute l'étendue de l'Isthme jusqu'à l'Acrocorinthe qui s'élève dans le lointain, de l'Est-Est/Nord au Sud-Ouest; la côte du Péloponnèse, plus rapprochée, développe des formes plus altières; les monts vigoureux de la presqu'île de

I35. L'île d'Égine fut, de juin I 828 à juin I 829, la première capitale de la Grèce qui luttait encore pour son indépendance. La ville y accueillait la Banque nationale, le Musée national, la Bibliothèque nationale et l'Imprimerie nationale. C'est dans la cathédrale d'Égine que le premier gouvernement libre avait prêté serment.

I 36. Le mot « Panhellénion » désigne tantôt le mont le plus élevé de l'île, tantôt l'institution créée vers I 3 I apr. J.-C. par l'empereur romain Hadrien, grand admirateur de l'histoire et de la culture grecques. Cette organisation, qui avait pour centre Athènes, avait une signification religieuse et politique puisqu'elle avait pour ambition de reconstituer un semblant d'unification hellénique, destinée à reproduire l'union de « tous les Grecs » face aux Perses.

I37. En réalité, ce temple a été voué à Apollon vers 500 av. J.-C. Vietty est tributaire des identifications traditionnelles puisque ce temple est considéré par tout le monde, au XIX ${ }^{\mathrm{e}}$ siècle, comme le temple d'Aphrodite. 
Méthane qui semble une île escarpée au devant, flanquée à droite et à gauche par deux îles (Moni, Angistri) qui lui font voir dans l'intervalle les côtes encore plus élevées de la Trézénie et d'Épidaure, et les îlots parsemés à l'entour comme les canots des grands bâtiments. Le rideau des monts éginétiques voile le côté d'orient, ligne vive et légère de monts argileux maritimes, dont les plus hautes cimes se terminent en pointes comme les vagues en pleine mer (la comparaison avec les vagues est bonne et juste). La forme physionomique de la terre éginétique est encore une des innombrables formes de la Grèce Protée : je n'ai rien vu de pareil ailleurs, elles ne sont ni grandes, ni esthétiques ni majestueuses : elles courent et s'élèvent avec légèreté. Il y [a] toujours un peu de la [illisible] de famille (son étendue d'orient à l'occident... du Nord au Sud...). Son ossature est composée de couches de grès entremêlées de couches d'argile. Cette dernière substance domine à l'extérieur et, comme de raison, détermine la forme légère de ses monts onduleux nés des vagues dont ils sont le simulacre concret (revêtus d'argile, ces monts helléniques sont plus [illisible] et plus vifs qu'ailleurs : on en fait d'ici la comparaison avec les grandes et fermes lignes de l'Attique et les formes colossales, compactes, athlétiques du Péloponnèse). Le calcaire perce quelquefois, bien plus rarement qu'à Salamine, la tête et le plateau des montagnes.

L'armature paraît être en porphyre : on trouve sur la grève et dans le lit des torrents de gros galets de cette substance, porphyre rougeâtre à petits grains. Il y a aussi, je crois, du basalte gris-brun (parois d'autels) ${ }^{13}{ }^{8}$. Ce pays argileux doit être fertile, mais peu varié de productions : les monts n'étaient pas assez hauts, les ruisseaux sont sur les $2 / 3$ de l'amont. L'olivier est l'arbre dominant, puis le figuier, l'amandier. Le pin hellénique couvre quelques montagnes et collines. On y voit le caroubier et le cyprès, le lentisque forme ses revers buissonneux et ses torrents sont bordés d'agnus-castus mais non de laurier rose... (Il y en a sans doute dans quelques plus hauts et plus frais vallons de l'intérieur).

L'eau un peu saumâtre près des rives n'y manque point viò̀ $\gamma \hat{n ̣}^{139}$. Il y a beaucoup de pâtures, des $\pi \varepsilon \rho^{\prime} \beta{ }^{\circ} \lambda \mathrm{or}^{\mathrm{I}}{ }^{\circ}$ en vignes et jardinages depuis qu'Égine est devenue la capitale de la Grèce - culture de coton comme ailleurs, etc. Que ne produisait pas la Grèce bien cultivée ? Toujours l'air courant de l'Attique, mais sensiblement plus chaud qu'à Salamine.

L'Île en somme est plus capitale, plus féconde, plus continentale que sa voisine du Nord, l'aride et sauvage Salamine (queue de l'Attique). Égine était et devait être en quelque sorte l'Angleterre de la Grèce. Sa marine rivalisa avec celle d'Athènes florissante, d'Athènes bien plus grande de territoire et de ressources. C'est ici qu'on

I38. Suit un paragraphe de six lignes barrées.

I39. «Sous terre ».

I40. «Enceintes, clôtures ». 


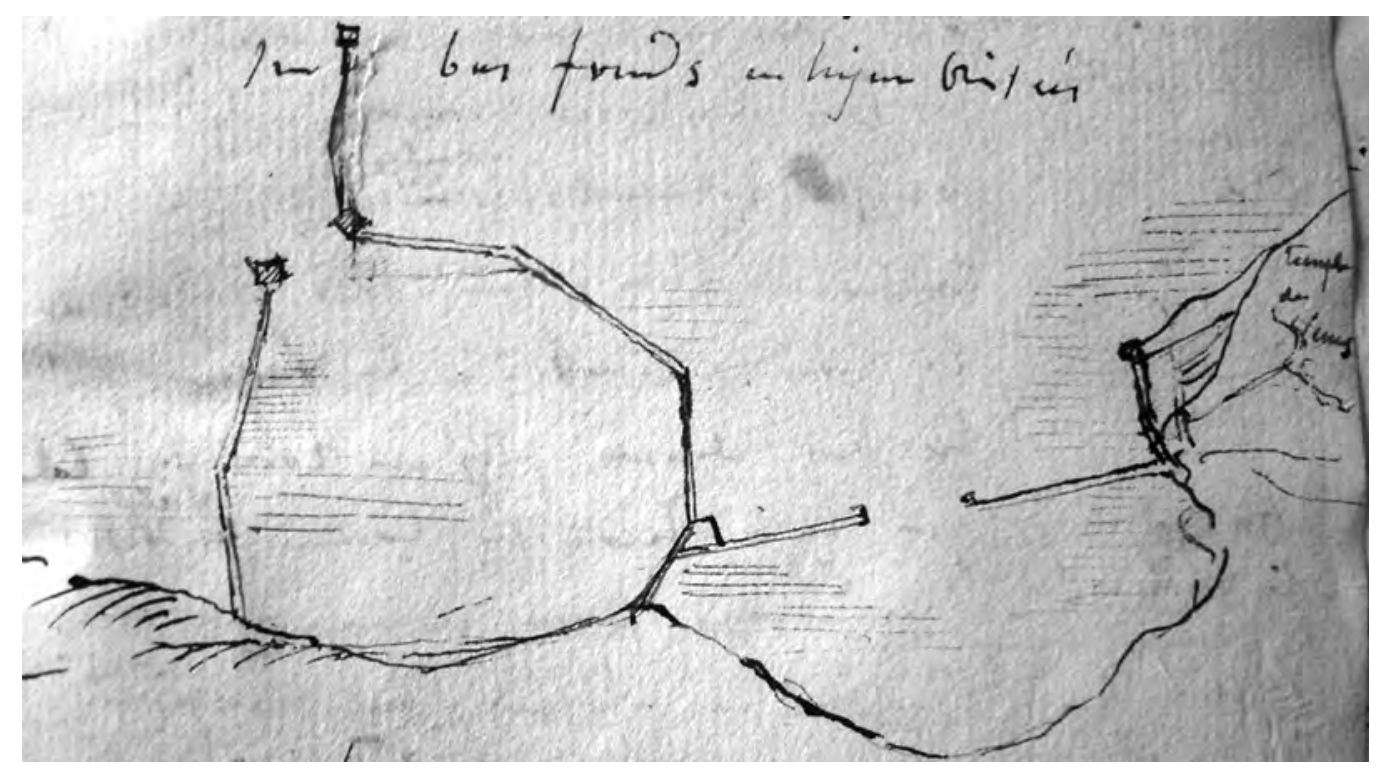

FIG. 7. - Les « deux ports » d’Égine.

peut étudier les constructions maritimes des anciens Hellènes : les chaussées de ses deux ports existent encore, quoique rongées par le temps et par les vagues. Pourquoi ces deux ports contigus ? Ils étaient dessinés par le rivage. Une seule enceinte eût été trop vaste pour résister aux vagues ; l'un peut-être servait de bassin pour laisser les navires, ainsi qu'à présent. - Ils sont tous deux factices, formés par des chaussées de grandes tailles construites sur bas fonds en lignes brisées (fig. 7).

L'entrée de l'un est au Sud-Ouest, de l'autre au Nord-Ouest; un grain en prolongement de chaussée, protège l'entrée du port contre les vents du large. À l'un des môles est un trou carré, de l'autre une chapelle. Il y avait probablement une tour à chacun. Ces ports sont peu profonds et ne pourraient recevoir de frégates. Ils étaient bons pour les bâtiments helléniques et paraissent d'ailleurs fort encombrés. Les chaussées ont généralement de Io à I 2 pieds de large, beaucoup plus en certains endroits qui demandaient plus de résistance comme un prolongement ou manche projeté dans la mer (à l'angle de jonction des deux ports est un plan carré détruit seulement dans la direction du Golfe de Corinthe, qui est le plus grand espace de mer de ce côté). À quelle hauteur étaient les chaussées ? Avaient-elles des parapets ? Maintenant, les parties les mieux conservées ont à peine un pied hors de l'eau. La partie sous l'eau est bien conservée : c'est un dallage presque régulier de grandes tailles de grès. Les tailles à fleur d'eau sont grugées par le choc continuel de la vague qui les bat depuis plus de 2000 ans (plus de 3000 peut-être) et qui les a recoupées comme les vieux rochers des 
rivages, percés de toutes parts et détruits en plusieurs lieux (on a planté sur les quais et sur les chaussées beaucoup de fûts lisses de marbre, très peu de grès, pour amarrer les navires). Depuis combien de siècles n'avaient-ils pas été réparés jusqu’à la dernière révolution ? On a comblé depuis peu des parties totalement rompues avec les matériaux du temple de Vénus dont on exploite les tailles de son bâtiment comme une carrière très commode : il n'y a de main-d'œuvre que celle de la fouille et du transport d'un quart de mille par mer. On a de belles tailles qui ne coûtent rien. Le prolongement est raccommodé avec les assises et les chapiteaux du temple de Vénus. On y voit trois chapiteaux de grès posés en moilons sur le tailloir [vérifier], déjà rongés par les flots (ils sont de proportions différentes : mais ce n'est pas raison qu'ils n’appartiennent pas au même temple ? Immense plage en I/ 2 cercle au $2{ }^{\text {ème }}$ port ; autour des 2 collines a été construit le lazaret qui doit avoir dévoré pour sa part une bonne partie du temple de Vénus au devant : plan sur 4 pieds I/2 d'élévation). Au delà du second port, jusqu'au cap du temple d'Aphrodite, le rivage était bordé d'un quai et des constructions soutenaient les fleurs de la colline du temple... On exploite aussi ces antiques travaux d'utilité publique... le temps hellénique est passé.

Si Égine est la ville d'étude maritime antique, c'est aussi celle des tombeaux. Pausanias dit qu'ils vénéraient spécialement Hécate $^{\mathrm{I} 4^{\mathrm{I}}}$ : les restes les plus capitaux de l'Antiquité éginétique sont les sépulcres. Excepté le cœur de la ville, les environs de l'agora, partout au loin les couches argileuses et de grès sont pavées de cryptes sépulcrales de formes, d'étendues, de profondeurs diverses. Ce serait une longue étude que

I4I. Pausanias, Description de la Grèce, II, 30: "Hécate est, parmi toutes les divinités, celle que les Éginètes honorent le plus : ils célèbrent chaque année les mystères d'Hécate qui ont été institués, à ce qu'ils racontent, par Orphée de Thrace. Son temple se trouve dans une enceinte, sa statue en bois a été réalisée par Myron ; elle n'a qu'un visage et qu'un seul corps. Alcamène est le premier, je crois, qui ait imaginé de réunir trois statues d'Hécate en une seule ; l'Hécate qu'il a faite ainsi est celle que les Athéniens nomment Epipyrgidia; elle se trouve près du temple de la Victoire sans ailes. Mais revenons à Égine : en se dirigeant vers le mont de Zeus Panhellénien, vous trouvez le temple d'Aphaïa, sur laquelle Pindare a fait un hymne pour les Éginètes. Les Crétois (car les traditions sur cette déesse sont particulières à leur pays ) disent que Carmanor, qui purifia Apollon du meurtre de Python, avait un fils nommé Eubolos. De Zeus et de Carmé, fille d'Eubolos, naquit Britomartis. Celle-ci se plaisant à la course, à la chasse, était aimée d'Artémis, qui l'adorait : mais un jour qu'elle voulait se soustraire aux poursuites de Minos, à qui elle avait inspiré de l'amour, elle se précipita dans des filets qu'on avait tendus pour prendre du poisson. Artémis la fit déesse, et les Crétois l'adorent, les Éginètes révèrent aussi Britomartis et disent qu'elle s'est fait voir dans leur île. Ils lui donnent le nom d'Aphaïa, et les Crétois celui de Dictynne. Le mont Panhellénion n’offre de remarquable que le temple de Zeus qui porte ce nom ; on raconte que c'est Éaque qui l'a fait bâtir. Quant à Auxésie et Damie, on sait que les Épidauriens, depuis longtemps privés de pluie, firent faire, d'après le conseil de l'Oracle, ces deux statues avec du bois d'olivier que leur donnèrent les Athéniens. Les Epidauriens, ne portant plus à Athènes les offrandes qu'on avait exigées d'eux pour ce don, en rejetèrent la faute sur les Éginètes, qui leur avaient volé ces statues : les Athéniens qui passèrent à Égine pour les récupérer, y perdirent la vie. Tout cela est raconté de manière détaillée dans les histoires d'Hérodote, et je n'ai pas le projet de répéter ce qui a déjà été si bien dit : j'ajouterai uniquement que j'ai vu ces deux statues et que je leur ai sacrifié de la même manière à peu près, qu'on a coutume de le faire à Eleusis. Mais c'en est assez sur Égine ». 
celle des tombeaux d'Égine. Leur système ressemble peu à celui de Salamine. Il est beaucoup plus capital. La plus grande partie est au Nord-Est et sur des plans assez hauts, ce qui déroute mes idées. Les uns sont creusés en simples bières, les autres, véritables hypogées, sont taillés dans le roc de grès à une profondeur souvent de 20 ou 25 pieds (IO-I 5 ), formant des salles parallélogrammes excavées au Nord et à l'Est. Celui du nouveau gymnase parât le plus capital (ces salles sont souvent contiguës sans communication). Les 3 colonnes qui soutiennent le plafond taillé, mis en place par la nature, sont de diamètres et de cannelures différents (NB : les parois sont enduites de stuc. C'était peut-être un temple d'Hécate ou un tombeau consacré [à] cette terrible divinité). Le chapiteau n'est qu'un moilon, non carré mais parallélogramme ? Il y a là de l'Égyptien ; mais ce qui parait inconcevable, c'est que les colonnes, cannelées, sont encore revêtues en partie d'un stuc qui les rendait colonnes lisses.

Ce monument remarquable doit être étudié (nous verrons si j'en aurai le temps). L'entrée de ces hypogées est toujours perpendiculaire : c'est une ouverture carrée, oblongue, ou circulaire en forme de puits ; le coin taillé au ciseau, hermétiquement fermé par des tailles, quelquefois au niveau du rocher, d'autres fois remontant par un pied de terre, plus ou moins.

On a bâti une Église souterraine dans l'un de ces mêmes tombeaux. On a percé pour l'entrée la berge de grès et pratiqué un corridor jusqu'à la crypte éclairée par l'ancienne ouverture du haut dont on a relevé la pierre scellée qui devait rester éternellement : on voit au delà du rond point [vérifier] chrétien, 2 bières monolithes en grès sur le couvercle, largement, helléniquement taillées au large ciseau, simples. j'ai pensé qu'elles avaient été placées dans les deux vides. On m’a dit qu'elles étaient au milieu du parallélogramme ?...

Une église dans un tombeau! Le temple du dieu vivant dans la demeure des morts! C’eût été chez les Grecs anciens un étrange sacrilège à moins, peut-être, qu'il n'eut été question de Pluton, d'Hécate ou de Mercure. Mais les Grecs modernes aussi superstitieux que leurs ancêtres, ont abjuré leurs traditions et leurs œuvres dont ils sont si loin aujourd'hui! Partout on trouve ces tombeaux, partout ils sont ouverts et fouillés. La plane colline du Nord-Est en est criblée. Ils s'avancent dans l'intérieur de la ville : en voici un dans un roc qui bordait une rue. La pierre de scellement devait être au niveau du rocher. Cette ville souterraine des ombres forme un vaste demi-cercle ; les tombeaux à colonnes et bien d'autres sont à l'autre extrémité au Sud-Ouest. La ville des morts était plus grande que celle des vivants.

Le nombre de vases exhumés des sépulcres est prodigieux. Chaque voyageur en emporte dans son pays. Les magistrats, les officiers en possèdent des collections plus ou moins considérables. Celle du Musée, sans être comparable aux collections d'Europe, est intéressante, et a le grand mérite de nationalité. Il y en a de toutes les pro- 


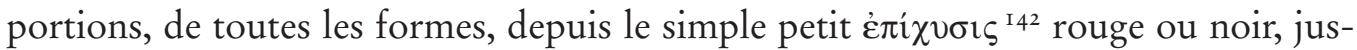
qu'au superbe vase à grands personnages. On y trouve tous les vases de ménage: écuelles, fioles, plats, huiliers, salières, coupes et sous-coupes, lampes etc., etc., etc. (Des vases de verre bleu ou coloré. Ils sont rares. Ces vases de formes extrêmement variées ont pour chacun un genre de peinture spécial : par ex. les vases allongés tels que le mien [vérifier] ont constamment en croquis le même convoi avec des chevaux;

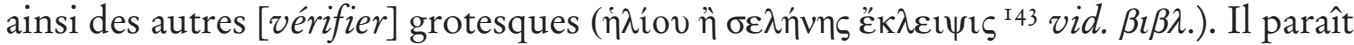
qu'on plaçait près des morts des vases usuels et des vases symboliques, ou que les vases usuels étaient symbolisés. On trouve des petites figures de terres cuites dans le système égyptien, d'autres demi-grec demi-égyptien, d'autres tout à fait grecques (les figures étaient peintes). Il y a des petites colombes de matière blanche ? Des miroirs de cuivre. Les cendres étaient placées dans de grands vases de terre cuite. Les puissants avaient des vases de marbre sculptés. Il y a des crânes au musée. Où étaient placées les épitaphes à palmettes, vases et inscriptions ? Où et comment étaient placés tous les vases, les cercueils ? Je voulais faire fouiller quelques tombeaux mais la position subalterne dans laquelle on m'a placé en une telle Expédition ne m’en a pas laissé, ni le temps, ni les moyens. J'ajourne donc l'étude que j'avais faite de cette partie si intéressante de l'ancienne histoire, le culte des morts, et je termine ces observations par celle que tous ces objets divers sont d'un goût de forme et d'exécution digne de la nature qui fut artiste par excellence. On n'y doit pas chercher la correction ou [la] précision du dessin. Ces figures, etc., étaient faites presque à main levée, comme nous peignons la fougère, et toujours du premier coup. Mais le style, la force de cette école incomparable, s'y fait connaître en tout et pour tout.

La ville d'Égine telle qu'elle est, est nouvelle, bâtie comme asile dans la dernière révolution : il n'y avait que 4 ou 6 maisons auparavant dans l'emplacement de l'ancienne cité d'Éaque. Cette ville-bourgade, sans rue, bâtie de maisons ou de groupes de maisons épars, est une espèce de labyrinthe où il est difficile de se reconnaître les premiers jours. La construction de ces maisonnettes (demeures) est sans caractère ainsi que cela doit être. Celles qui ne sont pas des grottes ou des huttes demi-sauvages sont les moins caractéristiques. Il n’y a pas de vestige du style oriental : cette influence recule de l'Europe. Les îles étaient restées plus vierges que le continent jusqu'à la puissante réaction de la civilisation européenne qui, selon l'état complexe des choses, devait agir d'abord sur les îles.

Il y a donc à Égine partout des constructions : du grec sauvage aux maisons pauvres, un style gréco-italico-français, aux palais de 2 ou 3 étages et la ville d'Égine

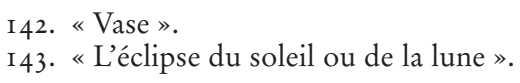


ne ressemble pas mal, aux grottes près, à un grand hameau de la basse province. Il y a cependant quelques constructions distinguées telles que le quai et surtout la maison d'éducation, vaste collège d'une construction simple et convenable, et où l'on a adopté le style gymnastique qui est ainsi revenu dans sa terre natale. J'ai assisté aux exercices de la jeune postérité hellénique, et je pense que ce n'est pas dans cette partie qu'elle trompera l'attente des philhellènes. Comment cela pourrait-il être autrement? Tout cela est au mieux; mais combien de restes de temples et d'autres édifices ont été fondus dans ces bâtardes constructions! Ainsi marche le monde; je ne dirai rien contre le gymnase, ou collège, parce qu'il est raisonnablement construit. Mais on doit crier Haro contre les colonnes barbares du portique ajouté à la cathédrale. Elles sont aussi turques que celles des mosquées, c'est-à-dire du goût des poteaux des granges de la Basse-Bretagne ; et elles sont taillées dans ces superbes symboles des hommes helléniques!

En descendant sur ces rives et montant sur ma berge élevée des moulins, le souvenir de Montmartre a frappé mon esprit. Tout n'est pas sur le compte des moulins à vents, dont je voyais une série de 8 , toujours à $\mathrm{I} 2$ ailes (système plus noble que le nôtre à 4). Mais ces berges blanchâtres d'argile ont quelque rapport avec celles, plus hautes, du gypseus de Montmartre. En possession de mon domicile, j'allai ensuite

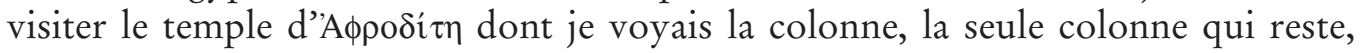

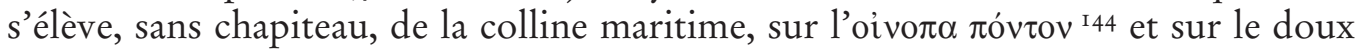
azur du ciel. Cette colonne extérieure (du diamètre de...) toujours dorique, qui n'est plus qu'un fût mutilé, ressemble à ces simulacres primitifs représentant tout un temple. Elle est restée seule sur l'épais et solide massif de tailles qui supportent

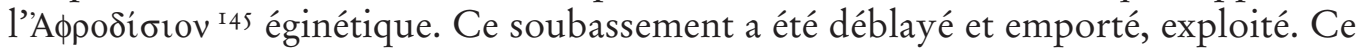
qui reste de ce beau travail de fondation manifeste l'esprit religieux des anciens hellènes, dignes disciples de l'Égypte, pour la masse de l'assemblage et la précision de la pose. Rien ne fut négligé pour assurer la stabilité du temple.

Cette colline argileuse, remplie de massifs en fondation jusqu'au bout de la mer, est devenue la carrière d'Égine. Elle a servi de forteresse dans le Bas-Empire car les massifs ne sont pas tous helléniques. La plupart est un amas de tailles et de fûts antiques de différents diamètres placés souvent à is pieds du sol. J'y ai vu une colonne de marbre verdâtre érodé comme celles de la plage de Mégare. Tout le temple, du moins les parties extérieures, sont en grès grisâtre, assez fin, qui est la pierre commune de l'île. Il y avait sans doute des marbres en dedans des murs de la

I44. CEnopia est l'ancien nom d’Égine, du grec oivorotós, « qui produit du vin ». En revanche, l'ex-

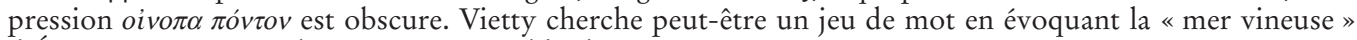
d'Égine, comme nous dirions une « mer d'huile».

I45. Statue d'Aphrodite. 
colline.... Je n'ai trouvé, dans tant de fouilles, aucun chapiteau ni vestige d'entablement ni un tambour de grandes colonnes. Tout cela est déjà métamorphosé dans les différentes constructions de la ville.

Au temps du Bas-Empire, une citerne fut pratiquée dans l'intérieur du temple. On éleva la terre en forme de glacis. On ne laissa qu'une colonne, les autres embarrassant, et sans doute pour servir de fanal. La colline fut garnie de remparts extérieurs. On ne peut douter que ce ne soit le temple désigné par Pausanias ${ }^{146}$. On ne

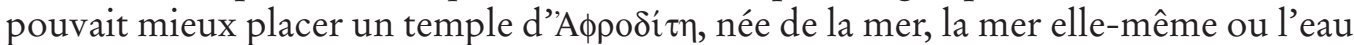
féconde, que sur cette colline dominant sur les flots. La déesse de son temple pouvait contempler son Empire.

Non loin de cette colline, en face du $2^{\text {ème }}$ port, en est une autre, beaucoup moins considérable mais plus abrupte, masse de rochers de grès sur le plateau de laquelle sont taillés un puits et un tombeau. Il devait y avoir là quelque édifice ; maintenant la surface est nue: les matériaux auront été retaillés pour quelques maisons qu'on y voit, ainsi qu'aux alentours.

\section{[Réflexions diverses]}

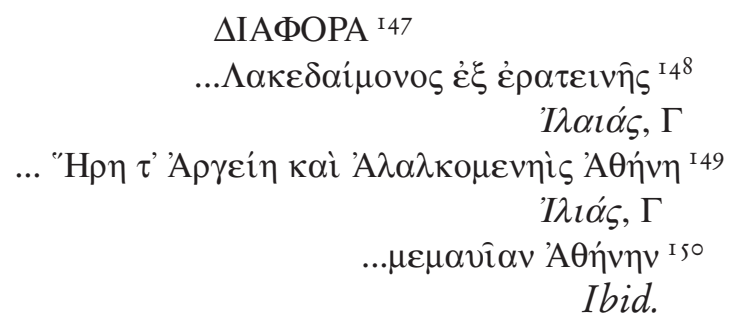

- À quelle époque ont commencé les théâtres grecs ? Existaient-ils du temps de la Guerre Médique?

- Je n'ai pas recherché le type national des Éginètes actuels : ils sont, dit-on, de race sarrasine (voy. l'hist.) et cette ville nouvelle est peuplée de pasteurs, de réfugiés Ipsariotes dont les femmes ont le plus élégant costume de la Grèce. Je viens d'en voir

I46. Voir n. I4I.

I47. Les pages 44 et 45 rassemblent des citations et des remarques éparses sans rapport direct avec ce qui précède et ce qui suit. Elles constituent un florilège de réflexions mis en évidence par une longue ligne horizontale, des tirets et des alinéas. Dès lors, le mot $\delta \iota \alpha \phi o \rho \alpha ́$ peut-il se comprendre dans le sens de « digression ", d'《excursus »?

I48. Homère, Iliade, III, $239:$ : (...) de l'aimable Lacédémone ».

I49. Ibid.., IV, 8 : « Héra d'Argos et Athéna d'Alalcomènes ».

I 50. Ibid.., IV, $73:$ : [...] brûlante Athéna ». 
une au nez un peu court, à la bouche un peu grande, mais d'un éclat ravissant. Une belle femme est ce qu'il y a de plus beau sous le soleil.

- La lune, en Grèce, colore le paysage des couleurs du soleil. Ce n'est point telle lumière vague à couleur douteuse comme dans le Nord. Ce sont les couleurs $\mathrm{du}$ jour affaiblies comme dans une éclipse. Ce phénomène n'est pas une des moindres beautés de la belle Hellade.

- Les Grecs ont toujours, ainsi que leurs pères, peu d'idée des hiérarchies sociales. Ils ne respectent guère la puissance et la richesse. Ils ne conçoivent pas ce que nous apportons : rang, sang. Voilà le véritable esprit d'égalité, inné chez eux, étranger chez nous, et que nous avons vainement tâché d'implanter en 93. Ils disent encore toi à tout le monde.

\section{[Suite du texte sur Égine]}

Ne reconnaissant pas d'abord la situation de l'ancienne Égine dans les plans peu modelés de la nouvelle, ne voyant point d'acropole, je me dirigeai au Nord-Est vers une haute colline au pied des montagnes (à $3 / 4$ de lieue de la ville). Après avoir traversé la plaine élevée des moulins, je vis sur celle de la plage une petite chapelle avec quelques vestiges de marbre. Plus loin, en revenant à l'Est, une autre chapelle au milieu d'une aire naturelle, peut-être un peu taillée, des rocs de grès, entourée de figuiers. Sur la porte est la moitié d'un marbre tumulaire avec une épitaphe (vid. $\gamma \rho \alpha \phi.)^{\text {II }}$; en dedans, des chapiteaux et bases ioniques. Là aussi fut un temple; plus loin, près d'une vigne, une espèce d'autel de basalte presqu'entier. Serait-ce l'autel dont parle Pausanias ${ }^{\mathrm{IS} 2}$ ? (Je ne le pense pas mais il faudrait fouiller). Sur cette colline que j'avais prise pour une acropole est une autre église entourée de tailles antiques déplacées; encore là un temple, mais la porte était fermée.

J'avais pris cette colline par le Sud. Je vis en montant qu'elle est composée de couches de grès fin qui fut exploité par les anciens Éginètes : on reconnaît parfaitement leurs travaux de carrière : ils n'avaient qu'à couper les blocs à fleur de terre... Quelques grands pins sont épars sur le revers. Leur forme générale est un parasol mais le feuillage est par touffes et ce sont à tout prendre des pins plus grecs qu'italiques. L'autre revers, semé de roches, où est une belle caverne, est planté de vignes, coton etc. Le tout par étage avec des murs de pierres sèches (presque comme sur la

I 5 I. L'incise « vid. $\gamma \rho \alpha \phi$. » pourrait renvoyer à un carnet contenant des croquis, des dessins et des inscriptions $(\gamma \rho \alpha \phi$. serait l'abréviation de $\gamma \rho \alpha \phi \varepsilon i \hat{o}$ v ou plus sûrement de $\gamma \rho \alpha \phi \hat{i} \varsigma$ qui peut désigner un ouvrage dessiné ou un recueil d'esquisses).

I 52 . Voir n. I4I. 
côte du Rhône). On voit dans les murs des blocs évidemment cyclopéens antiques et, dans un lieu, les restes manifestes d'une de ces vieilles merveilles posées sur le roc qui a été dressée à la pointe (vid. $\gamma \rho \alpha \phi$.). C'était donc là l'acropole d'Égine ou un fort pour défendre cette partie de la côte (on voit très bien Athènes de cette hauteur). Le chemin pour retourner à la ville est souvent taillé dans le rocher de grès ; ce doit être un ancien. Ce lieu, étant à l'entrée des montagnes, est bien plus agréable que la côte aride de la ville, plus modelée : des lits de torrents à sec sont du moins bordés d'oliviers et de figuiers, de lentisques etc. On voit des vignes, des jardins, des fermes. Le pays ombragé, cultivé, est riant d'un champêtre égal et léger, insulaire de Grèce, éginétique.

Que cette colline soit ou non l'acropole d'Égine, la ville n'était pas à l'entour (voy. plus haut). Dans un grand espace intermédiaire entre la pointe et la nouvelle ville, on ne trouve aucun vestige antique si ce n'est des sépulcres. Il faut chercher la ville ancienne dans la moderne. Le terrain s'abaisse grandement depuis le chemin des monts jusqu'à la mer de la même manière qu'à Corinthe, mais en plans plus légers (et il n'y a pas de ressemblance de proportion [vérifier] à l'égard de l'Acrocorinthe et de la vaste plage corinthienne). Revenu sur la hauteur du moulin, je cher-

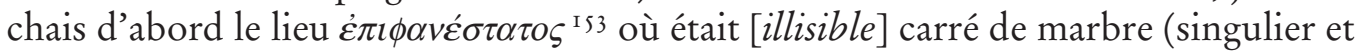
historique monument; [illisible] habités sur les berges). Plusieurs hauteurs planes, presqu'égales, dominent la ville. Sur l'une est un petit jardin naturellement creusé dans les couches de grès. Il y a beaucoup à Égine de ces creux laissés par les couches de grès. Sur une maison alentour un petit morceau de marbre en marbre où on lit

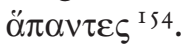

Je recherchai l'emplacement des temples d'Apollon et de Diane, d'Esculape, de Bacchus, de la Victoire. Sans [illisible], j'ai trouvé 3 chapiteaux doriques en grès dont l'un est dans une encoignure de maison, l'autre sert de banc et le troisième de margelle de puits (margelle fort originale et point inélégante). Et où étaient le théâtre et le stade ? On doit reconnaître au moins la place de ces grands édifices : je ne l'ai point reconnue. Où était du moins l'agora ? Elle était, je crois, à peu près à la place du bazar actuel non loin du port, où sont des auberges et cafés. On trouve à côté un cube de marbre blanc sur lequel sont écrits les noms de: Charicléa fille d'Aristocléides; Phoinissa fille d'Eritimos; Callimachos fils de Callippos ? L'inscription paraît complète et le cube, sans mordant, avoir été un piédestal ou socle. On plaçait des statues de héros ou législateurs ou des Hermès dans l'agora, des lois civiles, etc., etc. Qu'était ceci ?

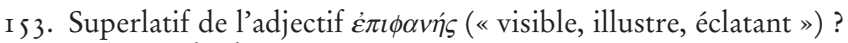
I 54 . «Tous » [les hommes ?]. 
En parcourant la ville, j'ai vu de plus une main colossale encastrée, 2 ou 3 autels de basalte. Un circulaire en grès.

Quelques inscriptions hiéroglyphiques, dans l'eau du port, et un fragment de celle d'un autocrator. Voilà donc ce qui reste de cette cité qui partagea la gloire d'Athènes au combat de Salamine! Quelques bas-reliefs au musée, presque tous funéraires, en épitaphes, des vases exhumés des sépulcres! De tant de temples, d'édifices, il n'est resté debout qu'un tronçon de colonne mutilée. Les tombeaux seuls ont survécu : la demeure des morts doit être en effet plus durable que celle des vivants. En vain, on a dispersé leurs cendres : les cryptes taillées dans le roc dureront autant que la terre. C'est ainsi que le voyageur est presque toujours déçu dans la patrie de l'héroïsme et des arts. Mille fois pillée depuis les Romains jusqu'à nos jours, cette terre si féconde en chefs-d'œuvre est restée nue sauf quelques tombeaux et ses productions inimitables sont entassées dans tous les cabinets de l'Europe.

La description du petit musée d'Égine exigerait une description spéciale en manière d'épisode (vid. infra). Il me semble que les morceaux de sculpture trouvés à Égine, le cheval surtout et son cavalier à pied, bas-relief mutilé qui a l'air d'avoir été un métopos, participent à la légèreté et à la vivacité du modelé de l'île. La sculpture n'en est pas moins grande, savante, vigoureuse et d'une autre façon que les basreliefs athéniens. Elle ne ressemble pas du moins à ce qu'on appelle ridiculement style éginétique d'après, je pense, les antiques figures du Panhellénion, comme si toutes les sculptures ou gravures de l'époque ancienne n'étaient pas, dans tous les pays de la Grèce, d'après un système pareil, aux nuances près du génie local! Les merveilles seules feraient foi de cette vérité qui devrait être banale.

De la ville d'Égine au Panhellénion, on compte 3 lieues (2 h. I/2 - 3 lieues), route à l'Est-Est/Nord. Ce doit être l'ancien chemin, souvent assez scabreux et tel qu'un sentier de berger. De la ville on monte toujours, doucement, jusqu'au col des

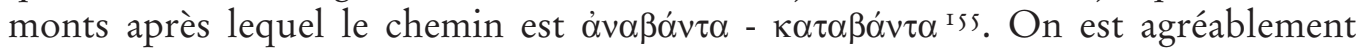
surpris à l'entrée des montagnes, de l'ombrage des oliviers et caroubiers qui peuplent ce paysage argileux. Le roc de grès, de basalte, et plus haut de calcaire, perce quelquefois la tête et le flanc des montagnes. On suit en remontant le cours d'un torrent desséché bordé d'agnus-castus. On voit quelquefois l'eau courir sur les galets ; lorsqu'on reconnaît l'illusion, l'on éprouve un sentiment pénible, analogue à celui que fait naître la vue d'un mort. Qu'est-ce en effet qu'une rivière sans eau, si ce n'est le cadavre d'une rivière ? À quelque distance de sa source, ce n'est plus une illusion : un filet d'eau limpide sort de la berge et coule quelque temps dans le lit du ruisseau.

I55. «Montant - descendant». 
Je cherchais dans chaque chapelle le long de la route les vestiges du temple d'Aphaïa ${ }^{156}$ où était gravée l'ode de Pindare en l'honneur des Éginètes. Je trouvai dans plusieurs des fragments insignifiants de marbre. Il y a bien peu de chapelles en Grèce où l'on ne retrouve quelques restes des anciens temples qu'elles ont remplacés. Mais la plupart de ces fragments méritent peu de considération. Si je retrouve quelque bel échantillon de l'École grecque ainsi qu'il en reste encore dans quelquesuns, il m'importe peu de reconnaitre par un morceau de marbre informe ou par un tambour de colonne, que là fut un des innombrables temples de la Grèce. J'excepte en cette indifférence les temples fameux et historiques tels que l'Héreion, le temple de Tégée, etc. et celui dont il s'agit. En ce cas, le moindre fragment dûment reconnu être à sa place dans ces glorieux édifices, est précieux : tant il est vrai que la gloire n'est point chose vaine, du moins ici bas! Mais dans toutes ces chapelles à droite et à gauche qui sont depuis Égine jusqu'au temple, il n'est pas facile de reconnaitre l'emplacement du temple illustré par l'ode de Pindare, surtout d'après le vague texte de Pausanias ${ }^{157}$. Et il faudrait beaucoup plus de temps qu'il ne m'est octroyé.

On arrive en vue d'un village bâti autour de la cime d'une montagne escarpée. Vue très pittoresque. Ce village ou ville s'appelle $\pi \alpha \lambda \alpha$ ı̀ Aï $\gamma v v \alpha$, la vieille Égine. Il faudrait gravir jusqu'à ce village demi-aérien pour reconnaître s'il fut une ancienne ville éginète ou s'il date de l'anarchie du Bas-Empire ainsi que le vieux Mistra (Vignes, beaux oliviers, jeunes et bons figuiers. Les vignes toujours basses comme en France. Raisins très variés : énormes et très petits, noirs, blancs, rosés, jaunes, peau dure, sucrés, bien ronds ou oblongs.). En bas est un petit ruisseau qui entoure un jardin ombragé de mûriers, d'oliviers, de figuiers sur lesquels se balance la tête élégante d'un palmier. Réduit solitaire et charmant, où l'on pourrait oublier les avantages de la civilisation... C'est le $6^{\text {ème }}$ dattier que j'ai vu en Grèce jusqu'ici. La Grèce n'est pas le pays des palmiers.

Le revers Est de la montagne semble être une masse de grands et petits rochers : ce sont d'énormes couches d'argile qui paraissent s'élever jusqu'au plateau du mont. Nous sommes sur l'autre revers de la chaine. Nous suivons un torrent entouré d'une épaisse bordure d'agnus-castus et qui coule en face de l'Attique. À droite, un autre village sur le flanc des montagnes aussi ; c'est un joli hameau, bien boisé des arbres ordinaires à Égine et de plus, de beaux cyprès helléniques qui s'élèvent de toutes

I 56. Le plus célèbre temple d’Égine, de style dorique, est un des trois piliers du triangle sacré formé par les temples du Parthénon, du Cap Sounion et d'Égine. Il fut très longtemps interprété comme un temple voué à Jupiter Panhellénios (en raison du mont Panhellénion à Égine), puis à Athéna. Construit à la fin du $\mathrm{VI}^{\mathrm{e}}$ ou au début $\mathrm{du} \mathrm{V}^{\mathrm{e}}$ siècle av. J.-C., il fait le lien entre la période archaïque et la période classique de l'art grec. Ses frontons sont actuellement conservés à la glyptothèque de Munich.

I 57. Voir n. I4I. 
parts en hauts obélisques. On s'aperçoit qu'Égine est moins sauvage que le reste de la Grèce : on voit de temps en temps de jolies petites blanches maisons de campagne. Nous avons rencontré les femmes des champs qui viennent vendre leurs denrées au bazar tout comme nos villageoises montées sur des ânes. Ainsi, l'intérieur de l'île d'Égine est bien plus agréable que ses rives, beaucoup plus boisé, généralement, il est vrai, d'arbres fruitiers. Il n'y a rien là de la sécheresse des entours de la ville et de tant de plages de la Grèce. C’est du doux champêtre hellénique. Néanmoins, dans les endroits les plus frais, on s'aperçoit, de par la capitalité des eaux et de la végétation, qu'on est dans une île, une île méridionale, et d'une très médiocre étendue. Mais cela vaut cent [fois] mieux que Salamine.

En approchant des côtes, les monts se couvrent du pin hellénique, toujours d'une forme mixte entre l'ombelle et le pin de France au Nord. Plusieurs sont d'une hauteur assez raisonnable et hauteur de cette taille d'arbuste ordinaire en ce pays. On peut dire du pin grec qu'il est plus français qu'italien et plus grec que français. On passe deux maisons des 2 côtés du sentier où les voyageurs peuvent trouver $\mathrm{du}$ pain, des œufs et quelquefois du vin. En avant, beau vallon en carrefour, bien planté en arbres ordinaires.

Arrivé sur un mont pinifère et à lentisque, on voit la mer et le Cap Sounion. Athènes est cachée, de même, par des monts dominant la côte, sur l'un desquels, plus rapproché et presqu'isolé, s'élèvent les colonnes du Panhellénion (l’île de Patrocle, etc.). C'est toujours avec une joie mêlé de respect qu'un homme honnête contemple les vieux et rares monuments de la religion des anciens hommes. À ce sentiment naturel pour ces offrandes de l'humanité à la suprême puissance, viennent se joindre, à l'égard des temples grecs, des idées d'hérö̈sme, la perfection intellectuelle et physique, qui les rendent l'un des objets les plus intéressants que nous puissions voir. Mais combien peu ont survécu au naufrage du temps! Aucun n'y a échappé tout entier, pas même le temple de Thésée qui a perdu ses peintures, ses statues, son sanctuaire. Le Panhellénion que les siècles et les hommes avaient si longtemps respecté a presque disparu sous les coups des Vénitiens, des Turcs et des Anglais. Ces derniers vandales ont mutilé de même celui de Phigalie dont les parties écroulées étaient du moins conservées. Que reste-t-il du temple de Corinthe et de celui de Némée ? io colonnes en tout dont plusieurs fracturées sur le point de tomber et toujours des colonnes extérieures... Il en reste 22 au temple d'Égine, quelques parties du mur de la cella, et vraisemblablement la plus grande partie de sa construction, excepté les sculptures et peintures, existe, ainsi qu’à Némée et Phigalion, entassée et brisée.

L'aspect de ce temple a un certain air de fête que n'ont pu lui ôter tant de siècles qui ont rongé ses colonnes dont plusieurs ressemblent à des rocailles de tuf sillonné par les eaux. Cette expression tient autant à son plan qu'à la proportion de ses parties. 
Hexastyle, il n'y a que I 2 colonnes aux côtés latéraux, y compris celles des angles (Il est ainsi relativement plus large que les autres temples. C'est la cause principale de son air noblement gai. Les autres sont : la largeur relative de ses inter-colonnes, les colonnes étant de courte proportion : voir texte). La colonne est courte; n'ayant que... diamètres (celles de Corinthe : ... du grand temple de Paestum... de Némée ... du Parthénon ...). Malgré cette courte proportion ; les colonnes ne paraissent pas lourdes : elles sont plus sveltes que celles de Corinthe, qui ont une expression beaucoup plus sévère ? Cela vient-il de leur grand retrait, du grand volume du chapiteau - de l'abaque, l'entour, le plus haut qu'il me semble avoir vu?

Ainsi qu'à tous les temples que j'ai visités jusqu'ici, il ne reste de l'entablement que des parties d'architrave (la corniche et la frise s'écroulant d'ordinaire avec le toit. Il est resté quelque parties de frise à celui de Némée qui n’était pas couvert). Cette architrave paraît très haute d'autant plus que le listel et les guttules sont peu considérables et d'un trait fin (hiéroglyphes antiques). Je n'ai pas mesuré le p[érimètre] du triglyphe trop rongé. Les métopes, refouillées de plus de 2 pouces, devaient avoir des bas-reliefs de marbre. Où sont-ils ? La corniche est de la composition ordinaire excepté le retrait de la cimaise. Les [illisible] ont 3 fois 6 guttules et celles de Némée 3 fois $3 .$. ? ? Les [illisible] sont inclinées comme partout.

Ce temple parait avoir été couvert de tuiles de terre cuite (trouvé 2 tuiles). Il est orienté presque du Nord-Est au Sud-Ouest, au côté Sud-Ouest. La cella est contournée, vers la porte, d'un socle, cube qui pourrait avoir supporté une statue ; l'autre côté de la porte, brisé et encombré, devait être de même.

L'intérieur de la cella était une longue salle encadrée d'un large socle sur lequel devaient reposer des colonnes: on trouve des tambours et des chapiteaux doriques [de] plusieurs dimensions, de très petits chapiteaux. Y avait-il 2 étages de colonnes ainsi qu'à Paestum ? Au bas de la porte de l'Est sont de singuliers ressauts... 2 colonnes flanquent à l'ordinaire l'entrée de la cella. Il y a beaucoup de rapport

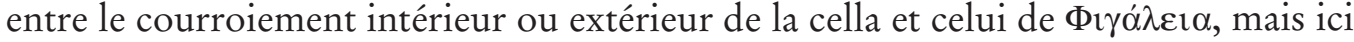
courait une plate bande, ou bandeau près de la corniche. Je n'ai vu aucun reste de caissons si abondants à Phigalie. Le plafond des vestibules devait être uni ou peint et peut-être l'intérieur hypèthre [vérifier].

Au Nord du temple, et à 50 pas, sur un revers et près de la cime de la colline de grès qui la supporte est une caverne naturelle dans laquelle se trouve un tambour déplacé d'une colonne dorique de 9i c[entimètres] de largeur qui a 36 cannelures! Elle devait être du temple : il paraît que là tout était dorique dedans et dehors ? Il est construit entièrement de grès qui était revêtu de stuc blanc d'une dureté et d'un timbre admirable. Il en est resté quelque partie aux endroits couverts. Ce gris d'un léger ton jaunâtre se trouve dans toute l'île (vide supra). Il paraît de choix et plus fin aux petites col[onnes] intérieures. On trouve beaucoup de fragments de marbre 
stat[uaire] à gros grain, dit de Paros. Ce doit être quelques fragments des frontons et des métopes. Mais n'y avait-il rien en marbre en dedans ? Il me serait d'une grande importance d'en retrouver le plan et la coupe intérieure.

Nous avons trouvé une partie fracturée d'une ancienne inscription sur pierre sur laquelle on lit $\Lambda$ ANIO. Il en existe une autre ou la même entière que M. Gropius ${ }^{158}$, le second Fauvel ${ }^{159}$, a copiée dans le temps des fouilles.

Ce temple était beaucoup plus pittoresque avant son déblaiement qu'il ne l'est à présent. Cela est général: les arbrisseaux, les arbres croissant au milieu des décombres, se groupant avec les colonnes, forment un contraste de végétation et de ruine, un effet de peintre et de poète qui disparaît dans les fouilles. Mais celles-ci font reconnaître le dessin des anciens édifices ; on ne peut tout avoir à la fois. Il existe un dessin fait avant les travaux de terrassement. On l'a communiqué à nos chefs qui ont jugé ce propos de [illisible], ainsi que les notes de l'Institut et tant d'autres choses!

Le Panhellénion est-il du temps d'Éaque ? On pourrait le croire d'après la narration plausible de Pausanias ${ }^{160}$. En ce cas, il serait bien antérieur à la guerre de Troie. Mais ce qu'on appelle ordre dorique était-il à cette époque reculée transformé de l'Orient et de l'Égypte aussi complètement que nous le voyons ici ? Il y a lieu d'en douter. Aux proportions près, le dorique du temple d'Égine est le même, absolument, que celui du Panthéon et de tous les doriques grecs. Il a pu être réédifié postérieurement ou édifié d'après des traditions historiques ou mythologiques de cet oracle de la Pythie et de la députation des Grecs auprès d’Éaque. Quoi qu'il en soit,

I 58. Consul d'Autriche en Grèce, M. Gropius fut l'ami de Lamartine qui lui rendit hommage dans son Voyage en Orient, en le qualifiant, lui aussi, de "second Fauvel », nom du consul de France à Athènes qui avait servi de guide à Chateaubriand: voir Lamartine, Souvenirs, impressions, pensées et paysages, pendant un voyage en orient (I832-I833), Paris, I835: "Aussi heureux que l'avait été autrefois M. Chateaubriand, conduit dans les ruines d'Athènes par M Fauvel, nous eûmes dans M. Gropius un second Fauvel, qui s'est fait athénien depuis trente-deux ans (...); homme d'érudition et homme d'esprit, M. Gropius joint, à l'érudition la plus consciencieuse et la plus approfondie de l'antiquité, ce caractère de naïve bonhomie et de grâce inoffensive qui est le type des vrais et dignes enfants de l'Allemagne savante. Injustement accusé par lord Byron dans ses notes mordantes sur Athènes, M. Gropius ne rendait point offense pour offense à la mémoire du grand poète : il s'affligeait seulement que son nom eût été traîné par lui d'éditions en éditions, et livré à la rancune des fanatiques ignorants de l'antiquité ; mais il n'a pas voulu se justifier, et quand on est sur les lieux, témoin des efforts constants que fait cet homme distingué pour restituer un mot à une inscription, un fragment égaré à une statue, ou une forme et une date à un monument, on est sûr d'avance que M. Gropius n’a jamais profané ce qu'il adore, ni fait un vil commerce de la plus noble et de la plus désintéressée des études, l'étude des antiquités. »

I 59. Voir Ph.-E. LEgRAND, «Biographie de Louis François Sébastien Fauvel, antiquaire et consul (1753-1838) ", Revue archéologique 30, I897, p. 41-66, I85-201, 385-404; 31, I897, p. 94-103, I85-223; C. G. Lowe, "Fauvel's First Trip through Greece», Hesperia, 5, 1936, p. 206-224, et surtout A. ZAMBON, «Fauvel et les vases grecs », Journal des Savants, 2006, p. 5-63 et i 85 -I 96.

i60. Voir n. I4I. 
son style, l'état de la pierre sous l'air sec qui l'enveloppe, démontrent une grande antiquité. Jusqu'à ce que l'on démontre catégoriquement qu'il est ou n'est pas un temple bâti par Éaque (démonstration qui serait un grand progrès dans l'histoire des arts et dans l'histoire générale), on peut, à la rigueur, la considérer comme le plus ancien temple de l'Europe.

Du côté de l'Est/Sud, une large plate-forme dallée servait d'avenue au temple

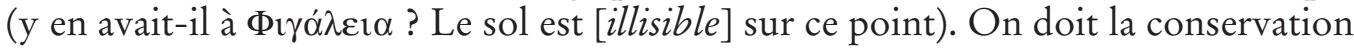

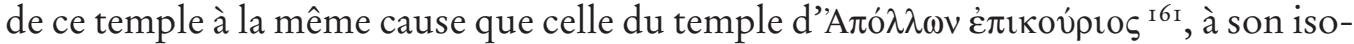
lement. Éloigné des habitations des hommes, il serait demeuré entier sans l'avide et aveugle rapacité des prétendus amateurs ou plutôt marchands anglais. À Égine, par toute la terre, cette race dévorante a exercé ses honteux ravages, fouillant, démolissant, brisant les rares et précieux restes de l'ancienne histoire de l'humanité qui, transposés en pièces dans la sombre Albion, sont déjà ternis et défigurés sous ce[tte] noir $[\mathrm{e}]$ atmosphère.

Un autre genre de vandalisme, plus stupide encore, peut-être, et surtout plus général, a concouru à défigurer les ruines respectables : la manie des petits esprits (grande majorité de l'esprit humain) d'écrire leurs noms sur les monuments célèbres, a été poussée ici au dernier degré d'extravagance. Presque toutes les pièces du temple entassées dans son enceinte sont entachées de ces noms obscurs, gravés souvent profondément dans la pierre et quelquefois d'un demi-pied de proportion (La chose est au point que les pièces en sont véritablement dégradées et d'après cela on ne peut douter que si les colonnes eussent été lisses, elles ne fussent toutes entaillées de même, aussi haut qu'on avait pu atteindre). Allemands, Anglais, Français, etc. tous ont cru devoir apporter leur signature sur le Panhellénion et les Grecs modernes n'ont pas manqué, par imitation, de se signaler de la même manière. Insensés, pauvres gens, idiots, troupe ignorante et rustre, pensez-vous vous illustrer en gravant vos noms indignes sur un monument illustre ? Si cette pierre que vous avez dégradée et profanée est encore longtemps conservée, la postérité saura [que] S....... N....... étaient des êtres vaniteux, ignorants et ridicules.

L'assiette du Panhellénion et des alentours rappelle ceux du temple d'A $\dot{\varepsilon} \pi$ «ov́pıos mais avec la modification de l'horizon attique: formes plus douces, moins colossales que celles du sauvage Péloponnèse. Ce ne sont point ici les hautes cimes, les rapides vallons du Lycée, ni la grande pyramide de l'Ithôme, ni les chênes et les rocs du Cotylion. Ce sont les élégantes montagnes d'Égine qui s'avancent en promontoires sur ses golfes, montrant quelquefois leurs flancs d'argile et leur tête rocheuse, d'autres fois légèrement ombragés de l'arbre de Cybèle. C'est la belle mer 
Saronique dont la couleur azurée ne semble qu'une teinte plus forte du pâle azur du ciel, mélangé de blanc et de rose. Quelle douce et brillante atmosphère ! Comment pouvoir le figurer sous notre ciel cru et terne ? Celui d'Italie, si beau, n'a point la douce magnificence du ciel de l'Attique, ni même le ciel du Péloponnèse, plus éclatant et plus varié. De cette colline élevée, l'Attique entière développe aux regards ses lignes vives et fermes, depuis le Cithéron jusqu'au Cap Sounion (Le milieu est voilé par des monts proéminents d'Égine); le Pirée, la plaine et la ville d'Athènes; Salamine qui semble tenir au continent: le mur [vérifier] découpé de la chaîne de Mégare. Le Cap Sounion ressemble à un grand tumulus à la pointe de l'Attique, couronné de son temple de Minerve ${ }^{162}$ que l'on aperçoit au loin au sommet du Mont. À quelque distance au sud, sur la même ligne, l'île d'Hélène sort un sein des flots, et plus loin encore, cette île rocheuse, St. George (Keos = [illisible $]$ par derrière au loin...).

Après avoir dessiné, mesuré, nous être reposés sous un pin, nous revînmes à Égine par le même chemin. Je ne crois pas qu'il y en ait d'autres.

\section{Second voyage au temple (voir notes et renseignements)}

Toujours la grosse main en moilons sur le point de sortir de la ville. Avant d'entrer dans la montagne, une église à droite sur un plateau, au milieu des oliviers. Il ne faut point chercher d'acropole entre les deux monts : cette pointe qu'on voit à Égine est un mont abrupt et sauvage qui est en avant de $\pi \alpha \lambda \alpha i \grave{\alpha}$ Aï $\gamma \imath v \alpha$. Celle-ci est une ville très remarquable par sa situation praeceps dominée par une tête de rocs noirs (fig. 8).

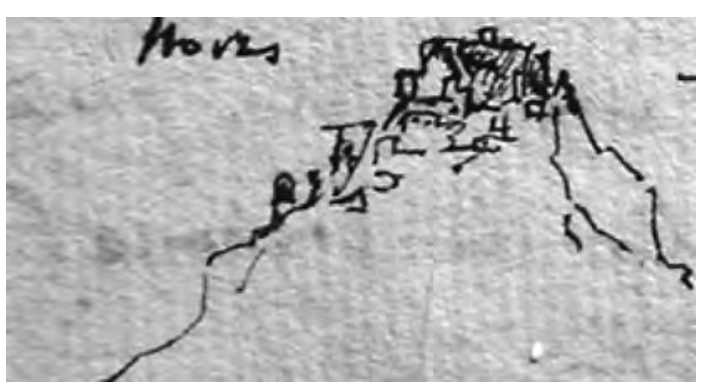

FIG. 8. - L’ancienne Égine.

Elle est très pittoresque presque déserte excepté quelques réfugiés d'Athènes. Tous sont venus à la ville. Cette ville où l'on dit qu'il n'y a rien d'hellénique me semble être de la catégorie du vieux Mistra, etc. : née de l'anarchie du Bas-Empire. La politique avait fait le tour en Grèce : dans le Moyen-Âge, on bâtissait sur les rocs, comme au temps d'Inachos. 
Les monts à Égine sont presque tous recouverts de terre argileuse. Le roc les perce assez rarement, le plus souvent en forme de dents isolées, cariées, dont les fragments sont épars sur les revers - rochers d'argile. Légère terre d'Égine, légères montagnes, légère irrigation, légère végétation. Ce n’est pas un continent. La route

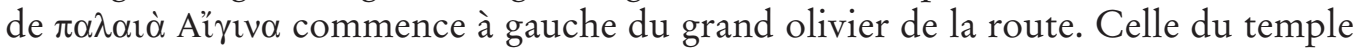
en avant d'une maison où est un berceau d'olivier ou de lentisque et, près de la jonction, un massif circulaire qui a dû être une aire.

Je ne pourrais oublier le monde à Égine qu'à mon petit jardin du palmier et au rameau vert des cyprès. Le pin annonce qu'on approche des côtes, l'intérieur est tout en arbres fruitiers ; figuiers, oliviers, caroubiers, arbrisseaux, agnus-castus, point de nérion, sur les fleurs. Quelles fleurs! Sans eaux! La solitude d'une île est plus intense que celle des continents. C'est la profonde solitude où l'on n'a de compagnie que les éléments... On se sent mieux séparé du reste du monde.

Le temple qu'on voit de loin et qu'on perd ensuite sur la colline m'a fait la même impression que la première fois. En l'examinant, il m'a semblé plus antique. Grande saillie, grands plans des chapiteaux dominant de fines moulures, hiéroglyphes I/2 égyptiennes bien accentuées en vieux hellénique $-\kappa \hat{v} \mu \alpha^{163}$ [illisible]. Des tombeaux trouvés au Sud-Est. J'y ai trouvé des débris de vases. Il est très important de vérifier ces citernes dont l'une communique à la grotte. Cette colonne

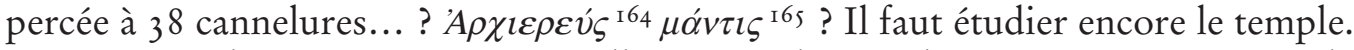

Quant à la vue, qui est attique, elle est grande pour la Grèce. J'ai été étonné de la grandeur du bassin du petit Céphise, ou Ilissus. La forêt d'oliviers paraît plus grande que celle de Corinthe.

Une construction blanche s'élève entre les arbres, à droite. Le revers d'une berge du Pirée apparaît. Avec la lunette, nous avons vu distinctement la ville de Cécrops, d'un autre point de vue que de Salamine. Le côté latéral Sud du Parthénon, la plaine d'où s'élèvent les huit grandes colonnes du Portique d'Hadrien, le monument de Philopappos ${ }^{166}$ en avant (ou la tour vénitienne des Propylées ([d'après] Blouet $\left.{ }^{167}\right]$ ).

163. "Bordure».

I64. «Grand-prêtre ».

165. «Devin, prophète, prophétesse ».

i66. Monument funéraire situé au sommet de la colline des Muses, sur le versant Nord-Ouest de l'Acropole. Il fut construit en I I 4 apr. J.-C. en l'honneur d'un prince romano-syrien, Gaius Antiochus Philopappos, bienfaiteur de la Cité d'Athènes. Ce monument de marbre et de pierre est recouvert de bas-reliefs représentant la vie de Gaius Philopappos.

I67. Abel Blouet (I795-1853), ancien prix de Rome, est le chef de la section d'architecture et le directeur de la publication des volumes portant sur les travaux d'architecture, sculptures, inscriptions et vues du Péloponnèse, des Cyclades et de l'Attique : voir F. Doulat, «Guillaume Abel Blouet, du village de Passy aux côtes de Morée, exemplarité ou exception du parcours intellectuel et artistique d'un enfant du peuple ", dans Livraisons d'bistoire de l'architecture, 5, 2003, p. 67-83. 
Cette vue qui donne l'idée d'une plus ample cité, offre [de] l'acropole [une] beaucoup moins pittoresque médaille que d'Ambelaki. Mais les environs de cette Athènes me paraissent l'être par excellence : quelle belle variété de plaines, de collines, de montagnes! Grande, vigoureuse, tempérée structure de la Grèce hérö̈que. Vivacité des formes tempérées sur un ensemble vaste, capital d'assiette...

Le ciel et la mer forment une harmonieuse gamme de tons azurés... 